\title{
DETERMINAÇÃO DO PADRÃO DE REGIÕES HETEROCROMÁTICAS NO GÊNERO Capsicum ATRAVÉS DE MÉTODOS DE BANDAMENTO
}

MARIA ANGÉLICA MACIEL MARTINHO FERREIRA

Bióloga

Orientadora: Profa. Dra. MARGARIDA L. R. DE AGUIAR-PERECIN

Dissertação apresentada à Escola Superior de Agricultura "Luiz de Queiroz", Universidade de São Paulo para obtençāo do título de Mestre em Agronomia, Área de Concentraçāo: Genética e Melhoramento de Plantas.

\author{
Piracicaba \\ Estado de São Paulo - Brasil \\ Junho - 1998
}


Dados Internacionais de Catalogação na Publicação (CIP)

DIVISĀO DE BIBLIOTECA E DOCUMENTAÇĀO - Campus "Luiz de Queiroz"/USP

Ferreira, Maria Angélica Maciel Martinho

Determinaçāo do padrāo de regiōes heterocromáticas no gênero Capsicum através de métodos de bandamento / Maria Angélica Maciel Martinho Ferreira. - -

Piracicaba, 1998.

58 p. : il.

Dissertação (mestrado) - Escola Superior de Agricultura Luiz de Queiroz, 1998. Bibliografia.

1. Bandamento cromossômico 2. Citogenética vegetal 3. Pimenta 4. Pimentão 5. Planta para condimento I. Título.

CDD 633.84 
FERREIRA, Maria Angélica Maciel Martinho. Determinação do padrão de regiões heterocromáticas no gênero Capsicum através de métodos de bandamento. Piracicaba, Dissertação (Mestrado) Escola Superior de Agricultura "Luiz de Queiroz", Universidade de São Paulo. 1998. 58p.

\section{ERRATA \& CORRIGENDA N.1}

\begin{tabular}{|c|c|c|c|c|}
\hline p. & item & linha & onde se lề & leia-se \\
\hline vii & resumo & 12 & ...que permitam... & ...que permitam a identificação... \\
\hline $\mathrm{ix}$ & summary & 2 & ... and aimed... & ... and it aimed... \\
\hline ix & summary & 5 & ...in cultivated... & $\begin{array}{l}\text {...in wild and cultivated species } \\
\text { of the genus Capsicum... }\end{array}$ \\
\hline ix & summary & 8 & ...in a poor cytotaxonomy & ...in poor cytotaxonomy... \\
\hline ix & summary & 12 & ...patterns telomeric... & ...patterns of telomeric... \\
\hline ix & summary & 13 & ...interspensed... & ...interspersed... \\
\hline ix & summary & 19 & $\begin{array}{l}\text {... of two NORs per diploid set so } \\
\text { that two of then were observed in } \\
\text { C. chinense... }\end{array}$ & $\begin{array}{l}\text {... of two NORs per diploid set in } \\
\text { c. chinense... }\end{array}$ \\
\hline $\mathrm{x}$ & summary & 2 & Analyses... & The analyses... \\
\hline $\mathrm{x}$ & summary & 4 & ... of in situ hybridization.... & $\begin{array}{l}\text {...of the techinique in situ } \\
\text { hybridization... }\end{array}$ \\
\hline $\mathrm{x}$ & summary & 7 & ...avaluation... & ...evaluation... \\
\hline $\mathrm{x}$ & summary & 8 & ...fluorescents... & ...fluorescent... \\
\hline 1 & 1. & 1 & ...é constituído... & ....sendo constituído... \\
\hline 1 & 1. & 15 & $\begin{array}{l}\text {...par de cromossomo } \\
\text { acrocêntrico... }\end{array}$ & $\begin{array}{l}\text {...par de cromossomos } \\
\text { acrocèntricos... }\end{array}$ \\
\hline 2 & 1. & 20 & ...trará... & ...trarāo... \\
\hline 5 & 1. & 15 & ...bactérias, virus e fungo... & ...bactérias, vírus e fungos... \\
\hline 6 & 1. & 14 & ...controvérsias na taxonomia... & $\begin{array}{l}\text {...controvérsias sobre a } \\
\text { taxonomia... }\end{array}$ \\
\hline 7 & 1. & 5 & ...geográficas dessas... & ...geográficas das... \\
\hline 8 & 2.3 & 13 & ...que o padrão de bandas- $\mathrm{C}$ era... & ...que o mesmo era... \\
\hline 8 & 2.3 & 25 & ...apesar desta... & ...apesar da... \\
\hline 10 & 2.4 & 3 & Estas metodologias... & As metodologias... \\
\hline 12 & 2.4 & 8 & $\begin{array}{l}\text {...segmentos cromossômicos que } \\
\text { apresentam baixa... }\end{array}$ & $\begin{array}{l}\text {...segmentos cromossômicos com } \\
\text { baixa... }\end{array}$ \\
\hline 12 & 2.4 & 8 & ...induzida por... & ...quando submetidas a... \\
\hline 12 & 2.4 & 9 & ...sendo um fenômeno... & ...sendo este um fenômeno... \\
\hline 13 & 2.4 & 19 & ...estas são desconhecidas... & $\begin{array}{l}\text {...estas regiões são } \\
\text {...desconhecidas... }\end{array}$ \\
\hline 16 & 2.4 & 7 & ...pode ocorrer... & ...podem ocorrer... \\
\hline 17 & 2.4 & 26 & ...em todas as espécies... & ...dentre todas as espécies... \\
\hline 18 & 2.4 & 14 & ... encontradas nos cariótipos... & Os cariótipos... \\
\hline 33 & 4.1 .1 & 8 & C. annum.. & Capsicum annum.. \\
\hline 33 & 4.1 .1 & 19 & ...apresentam bandas... & ...apresentam com bandas... \\
\hline 34 & 4.1 .1 & 1 & C. chinense... & Capsicum chinense... \\
\hline 36 & 4.1 .1 & 3 & C. baccatum.. & Capsicum baccatum... \\
\hline 40 & 4.2 . & 13 & ...quanto ao cariótipo... & ...em relação ao cariótipo... \\
\hline 49 & 5. & 18 & ...pode ser rica... & ...podem ser ricas ... \\
\hline 56 & Referências & 2 & $\ldots 1961 \ldots$ & $\ldots 1962 \ldots$ \\
\hline 56 & Referências & 22 & $\ldots 1993 \ldots$ & ..1990... \\
\hline 57 & Referências & 12 & $\ldots 1981 \ldots$ & $\ldots 1971 \ldots$ \\
\hline
\end{tabular}


Ao meu marido Ramiro, pela compreensão, incentivo e carinho e as minhas filhas Ana Gabriela e Tatiana, razão de toda uma existência 
$\grave{A}$

Minha mãe Albertina, Maria do Carmo, Vanessa. 


\section{AGRADECIMENTOS}

A Deus, pela vida.

À Prof ${ }^{\text {a }}$. Dr ${ }^{\mathrm{a}}$. Margarida L. R. de Aguiar-Perecin pelos conhecimentos e orientação.

À Universidade Federal de Mato Grosso do Sul, pela oportunidade da realização do curso.

Ao Departamento de Ciências Naturais do Centro Universitário de Três Lagoas/UFMS, na pessoa da Prof ${ }^{a}$. Dr ${ }^{a}$. Maria Lígia de Macêdo, pelo apoio e compreensão na fase de conclusão deste trabalho.

A Prof ${ }^{a}$. Dr ${ }^{a}$. Maria Elizabete Silva Caballero, pelo incentivo e amizade.

Aos colegas do Departamento de Ciências Naturais/CEUL/UFMS, pelo apoio e companherismo.

Aos professores do Curso de Pós-Graduação do Departamento de Genética da ESALQ/USP pelos ensinamentos transmitidos.

À Janay Almeida dos Santos e Mônica Rosa Bertão, pela amizade, paciência, apoio e sugestões durante a elaboração deste trabalho. 
Aos colegas José Raulindo Gardingo e Mateus Mondin, pelo companherismo, apoio e incentivo.

Aos funcionários do Laboratório de Citologia, Carlos Alberto Verissimo e Sílvia Cristina Menuzzo Molina, pela convivência, dedicação e amizade.

Aos funcionários do Departamento de Genética da ESALQ/USP, Antônio Pádua Gorga e Silvana M. Gregório, pela coloboração.

À CAPES, pela concessão da bolsa de estudo. 


\section{SUMÁRIO}

Página
RESTM

RESUMO .............................................................. vii

SUMMARY .......................................................... ix

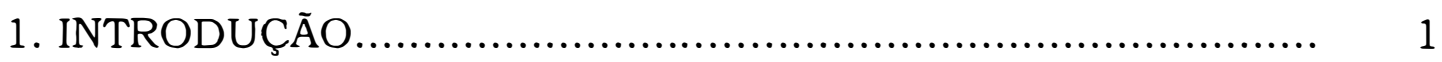

2 REVISÃO DE LITERATURA....................................... 4

2.1 Taxonomia.. ............................................................ 4

2.2 Origem, diversidade e distribuição geográfica..................... 6

2.3 Estudos citogenéticos no gênero Capsicum......................... 7

2.4 Bandamento cromossômico............................................ 9

3 MATERIAL E MÉTODOS.................................................. 20

3.1 Material............................................................. 20

3.2 Métodos............................................................. 20

3.2.1 Germinação de sementes........................................... 20

3.2.2 Obtenção de metáfases mitóticas................................... 21

3.2.3 Bandamento-C................................................... 21

3.2.4 Coloração com nitrato de prata..................................... 24

3.2.5 Bandamento-Q.................................................... 25

3.3 Análise citológica........................................................ 25

4 RESULTADOS E DISCUSSÃO...................................... 27

4.1 Bandamento-C....................................................... 27

4.1.1 Espécies cultivadas............................................... 33

4.1.2 Espécie selvagem............................................... 37

4.2. Bandamento-Ag-NOR.............................................. 39

4.3 Bandamento fluorescente........................................... 47 


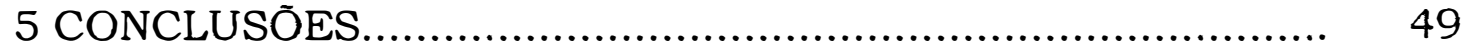

REFERÊNCIAS BIBLIOGRÁFICAS..................................... 51 


\title{
DETERMINAÇÃO DO PADRÃO DE REGIÕES HETEROCROMÁTICAS NO GÊNERO Capsicum ATRAVÉS DE MÉTODOS DE BANDAMENTO
}

\author{
Autor: MARIA ANGÉLICA MACIEL MARTINHO FERREIRA \\ Orientador: Dra MARGARIDA L. R. DE AGUIAR-PERECIN
}

\section{RESUMO}

O presente trabalho faz parte de uma linha de pesquisa desenvolvida no Departamento de Genética da ESALQ/USP e visa a padronização de metodologias de bandamento-C e de coloração pelo nitrato de prata, para investigação do padrão de distribuição da heterocromatina constitutiva, bem como detecção de regiões organizadoras de nucléolo (RONs) ativas, em espécies cultivadas e selvagens do gênero Capsicum.

As espécies do gênero Capsicum apresentam cariótipos muito similares o que dificulta uma identificação mais precisa dos cromossomos, comprometendo um bom desenvolvimento de estudos de citotaxonomia e de evolução no gênero. Desta forma, é importante o uso de técnicas que permitam marcadores cromossômicos nestas espécies.

A aplicação da metodologia de bandamento-C permitiu o estabelecimento do padrão de bandas teloméricas, centroméricas e raras intercalares, nas espécies $C$. annuum, C. chinense, C. baccatum e $C$. praetermissum, confirmando a variabilidade inter e intraespecifica existente no gênero, mencionada na literatura. Os dados de $C$. praetermissum são apresentados pela primeira vez. As espécies 
estudadas divergiram quanto ao conteúdo e distribuição de heterocromatina.

O uso de coloração pelo nitrato de prata permitiu a identificação de duas a quatro RONs por complemento diplóide, sendo observados duas em C. chinenese, e quatro nas variedades 435 e 2042 de $C$. baccatum e em $C$. praetermissum. A análise dos núcleos interfásicos da var. 530 de C. baccatum permitiu a identificação de cinco a seis nucléolos. A aplicação da técnica de hibridação in situ poderá auxiliar na identificação precisa do número de sítios de rDNA presentes no genoma dessas espécies.

A avaliação preliminar da var. 2042 de C. baccatum com o uso do fluorocromo quinacrina não mostrou a ocorrência de bandas fluorescentes, sugerindo que nesta variedade a heterocromatina pode ser rica em bases $\mathrm{G}+\mathrm{C}$.

Estudos mais detalhados em diferentes espécies cultivadas e selvagens do gênero Capsicum, através de técnicas de bandamento cromossômico possibilitarão uma melhor caracterização de espécies, variedades e cultivares, bem como um melhor entendimento da evolução cromossômica do gênero. 


\title{
PATTERNS DETTERMINATION OF THE HETEROCHROMATIN REGIONS IN THE GENUS Capsicum THROUGH BANDING METHODS
}

\author{
Author: MARIA ANGÉLICA MACIEL MARTINHO FERREIRA \\ Adviser: Dra. MARGARIDA L. R. DE AGUIAR-PERECIN
}

\section{SUMMARY}

The present work is part carried of a research line at developed at the Genetics Department, ESALQ/USP, and aimed to establish Cbanding and silver nitrate staining methodologies, to investigate the heterochromatin pattern, as well as the detection of active nucleolar organizer regions (NORs) in cultivated and species of Capsicum genus.

The especies of the genus Capsicum show highly similar karyotypes and a precise chromosome identification is difficult in species of the genus, resulting in a poor cytotaxonomy and evolution studies of the genus. Therefore, it is important to employ techniques for the vizualization of chromosome markers in these species.

The utilization of C-banding methodology led to the establishment of the patterns telomeric, centromeric and rare interspensed bands of $\mathrm{C}$. annuum, $C$. chinense, C. baccatum e $C$. praetermissum, confirming the intra and interspecific variability within the genus reported in the literature. The C-band pattern of the $C$. praetermissum is reported for the first time. The species studied showed different heterochromatin content and distribuition.

The employment of silver nitrate staining allowed the identification of two NORs per diploid set, so that two of then were 
observed in C. chinense and four in varieties 435 and 2042 of $C$. baccatum var. 530 and also in C. praeternissum. Analyses of interphase nuclei of $C$. baccatum var. 530 permitted the identification of five to six nucleoli. The application of in situ hybridization may help the precise identification of the number of rDNA sites present in the genome of this species.

Preliminary avaluation of C. baccatum var. 2042 using the fluorocrome quinacrine did not show the occurence of fluorescents bands, suggesting that in this variety the heterochromatin may be CG rich.

More detailed studies in different cultivated and wild species of the genus Capsicum, using chromosome banding will make possible a better characterization of the species, varieties and cultivars, as well as a better understanding of the chromosome evolution of the genus. 


\section{INTRODUÇÃO}

O gênero Capsicum pertence à família Solanaceae, é constituido de plantas conhecidas como pimentas e pimentões, muito cultivadas em todo o mundo devido ao seu potencial econômico. Estas espécies, apresentam uma ampla variabilidade, condicionada pelos seus principais caracteres morfológicos, tais como formato, tamanho, cor e posição de flores e frutos, número de pedicelos por nó, folhas, entre outros, o que condiciona uma grande diversidade de tipos.

Em decorrência desta diversidade e também devido à sua importância econômica, o gênero vem se constituindo em um material de interesse para pesquisas nas áreas de Citogenética, Evolução, Biologia Molecular e Biotecnologia.

A análise de cromossomos mitóticos de espécies e variedades cultivadas e selvagens, tem evidenciado cariótipos muito similares, caracterizado pela presença de onze pares de cromossomos metacêntricos ou submetacêntricos e um par de cromossomo acrocêntrico presentes em todas as espécies analisadas, muito característico do gênero (Sinha, 1950; Ohta, 1962; Carluccio \& Saccardo, 1977; Limaye \& Patil, 1989; Pickersgill, 1971, 1977; Moscone et al., 1990, 1993, 1995, 1996; Bertão \& Aguiar-Perecin, 1991; Bertão, 1993).

Os dados cariológicos obtidos para espécies cultivadas e selvagens, tem evidenciado um número cromossômico básico $\mathrm{x}=12$, 
como é comum em outros gêneros de Solanáceas. Número cromossômico diferente, também tem sido citado para algumas espécies de Capsicum, onde $\mathrm{x}=13$, sendo os cromossomos extras, pequenos $\mathrm{e}$ acrocêntricos facilmente identificáveis.

A despeito da similaridade cariotípica encontrada em todas as espécies analisadas de Capsicum, algumas diferenças foram encontradas permitindo assim caracterizar espécies e variedades. Estas diferenças referem-se a variações no comprimento dos cromossomos, posição do centrômero e número, tamanho e posição do satélite entre os pares cromossômicos (Carluccio \& Sacardo, 1977; Limaye \& Patil, 1989, Pickersgill, 1991; Bertão, 1993; Moscone et al., 1990, 1993, 1995, 1996).

Esta similaridade entre os cariótipos dificulta a identificação precisa dos cromossomos, bem como a caracterização das espécies através da análise citogenética. Desta forma as diferentes técnicas de bandamento vem se constituindo em ferramentas importantes em estudos citogenéticos para espécies cultivadas e selvagens de plantas, contribuindo para estudos de identificação e caracterização cromossômica. Estas técnicas aplicadas no gênero Capsicum, com certeza trará grandes contribuições para estudos de evolução cariotípica dentro do gênero.

Shopova (1966) avaliando três espécies cultivadas (C. annuum, C. frutescens e C. baccatum), através de tratamento a frio seguido de coloração pelo método de Feulgen, mostrou que estas espécies apresentam variação na quantidade e distribuição de heterocromatina. As três espécies apresentaram grande quantidade de heterocromatina na regiāo centromérica. C. pubescens particularmente se diferencia por apresentar heterocromatina na região telomérica. 
Poucos estudos sobre padrões de heterocromatina em cromossomos mitóticos de Capsicum foram feitos até o presente. Além de Shopova (1966), somente Moscone et al. (1993, 1995 e 1996), investigou o padrão de distribuição de heterocromatina em espécies selvagens e cultivadas, através da metodologia de bandamento-C, coloração pelo nitrato de prata e com fluorocromos base-específicos.

Em continuidade ao trabalho de análise do cariótipo, através de coloração convencional de espécies do gênero Capsicum, desenvolvido por Bertão (1993), no laboratório de Citologia do Departamento de Genética da ESALQ/USP, o presente trabalho teve como objetivo determinar o padrão de regiões heterocromáticas através da metodologia de bandamento- $C$, que evidencia região ricas em sequências altamente repetitivas de DNA em espécies domesticadas e selvagens, bem como evidenciar as regiōes organizadoras de nucléolo (RONs) pela técnica de coloração com nitrato de prata, estabelecendo um padrão de bandas que certamente trará contribuições aos estudos taxonômicos, de sistemática e de evolução cariotípica do gênero. 


\section{REVISĀO DE LITERATURA}

\subsection{Taxonomia}

O gênero Capsicum da família Solanaceae, distribuído no Novo Mundo, compreende um grande número de espécies selvagens $\mathrm{e}$ cultivadas conhecidas como pimenta e pimentões, que muitas vezes ocorrem como componentes de vegetações "naturais. A ampla variabilidade apresentada pelo gênero quanto a caracteres morfológicos importantes, tem condicionado uma diversidade grande de tipos, que tem levado a uma indefinição quanto a nomenclatura varietal ou divisão subgenérica do gênero.

Controvérsias quanto à classificação taxonômica do gênero Capsicum datam do século passado. Linneaus em 1825, descreveu as espécies C. annuum e C. frutescens com base no hábito anual e perene, respectivamente. Esta classificação, porém, foi contestada em outros estudos taxonômicos que consideravam $C$. annuum uma variedade de $C$. frutescens, além de introduzirem uma nova espécie C. pubescens (Heiser et al., 1951). Classificações mais recentes incluem cinco espécies domesticadas facilmente identificáveis: C. annuum, C. chinense Jacq., C. frutescens L., C. pubescens R \& P. e C. baccatum L. (Heiser \& Pickersgill, 1969). Geralmente todas as espécies domesticadas são caracterizadas por certas mudanças que acompanham a domesticação. No caso de 
Capsicum as cinco espécies domesticadas exibem frutos maiores que as espécies nativas.

A taxonomia do gênero Capsicum é muito dificil e confusa, sendo as espécies cultivadas e selvagens relacionadas, subdivididas em caráter provisório considerando-se a cor predominante da corola, sendo classificadas em "grupo de flores brancas" e "grupo de flores púrpuras" (Jensen et al.,1979; McLeod et al., 1979; Pickersgill, 1991). A dificuldade de se avaliarem taxonomicamente as espécies de Capsicum tem sido superada adotando-se uma chave de classificação, onde analisa-se um conjunto de caracteres morfológicos (Andrews, 1984).

As espécies cultivadas podem se cruzar com espécies selvagens afins, produzindo híbridos viáveis e férteis. Estas espécies selvagens, em princípio, apresentam potencialidade para no futuro serem utilizadas como fonte de resistência a doenças causadas por bactérias, virus e fungo (Casali $\&$ Couto, 1985).

Trabalhos recentes têm proposto que as formas cultivadas deste gênero podem ter origem monofilética ou polifilética à partir de formas selvagens ou relativamente selvagens. Baseando-se nos padrões de bandamento-C, coloração pela prata e com fluorocromos, Moscone et al. $(1993,1995,1996)$ sugerem três linhas evolucionárias diferentes para explicar a origem das cinco espécies cultivadas: $C$. annuum, $C$. frutescens, C. chinense, C. pubescens e C. baccatum var. pendulum. No primeiro grupo estariam incluídas $C$. frutescens, $C$. chinense $e C$. annuum, consideradas espécies distintas e isoladas reprodutivamente, embora estejam ligadas por caracteres morfológicos e de isoenzimas. O padrão de bandamento-C e de RONs observado nestas espécies, sugerem uma relação próxima entre $C$. chinense e $C$. frutescens, que teriam como centro de origem o Norte da Amazônia, enquanto $C$. annuum, teria se originado no México. Os referidos autores não excluem 
também, a possibilidade de que nessas duas áreas, estas espécies cultivadas pudessem ter se originado independentemente. A segunda linha evolucionária inclui $C$. baccatum var. pendulum sendo sugerida uma origem à partir da espécie selvagem $C$. baccatum var. baccatum (Moscone et al., 1996), tendo como centro de origem a Bolivia (Eshbaugh, 1970). Como terceira linha evolucionária, tem sido sugerido que o grupo de flores púrpuras com extensa diversidade no Andes Central - C. eximium e a endêmica boliviana $C$. cardenasi, poderiam ser os ancestrais de C. pubescens.

Embora trabalhos de caracterização cariotipica venham sendo realizados no gênero, quer com o uso de coloração convencional, ou diferentes técnicas de bandamento cromossômico (C, RON e fluorescente) e hibridação molecular in situ (Tanksley, 1988), há ainda controvérsias na taxonomia do gênero.

\subsection{Origem, diversidade e distribuição geográfica}

O gênero Capsicum é originário do Novo Mundo, tendo sua distribuição geográfica ampliada após a colonização das Américas. Paralelamente a sua domesticação, foram fixados vários tipos de taxons para cada espécie, existindo atualmente um grande número de variedades fenotipicamente distintas. No estudo realizado por Datta (1968) em C. annuum, foram encontradas variações morfológicas significativas na estrutura dos cromossomos. É possivel que essas variações tenham ocorrido devido a pressão seletiva para fenótipos específicos durante a domesticação.

De maneira geral as espécies domesticadas são caracterizadas por certas mudanças que acompanham a domesticação. Normalmente 
plantas cultivadas tem frutos maiores, porém em menor quantidade que seus parentes selvagens, embora a produção de sementes por plantas continue a mesma.

Eshbaugh (1976) menciona que para entender a evolução nesse grupo é necessário considerar que a distribuição geográfica dessas espécies domesticadas tenha sido modificada pela mão do homem. Algumas dessas espécies alcançaram vasta distribuição pelas mãos dos indianos, enquanto outras atingiram sua distribuição através das atividades dos espanhóis, ou ainda pelo contato com o homem moderno. É claro que as espécies domesticadas que foram por sua vez isoladas umas das outras agora integram os vários taxons domesticados.

\subsection{Estudos citogenéticos no gênero Capsicum}

Estudos citogenéticos de um modo geral consideram que análises do complemento cromossômico nos diversos grupos de seres vivos podem fornecer informações básicas para a caracterização citológica, permitindo a identificação de espécies. Nos estudos de cariótipos de Capsicum, os parâmetros usados para identificar os cromossomos têm sido o comprimento dos cromossomos, o comprimento do braço longo e do braço curto, bem como a relação de braços.

A análise da evolução cromossômica dentro do gênero tem mostrado um número cromossômico básico $\mathrm{x}=12$, sendo $2 \mathrm{n}=24$, embora variantes para este número cromossômico também tenha sido encontrados. Datta (1968) estudando cromossomos somáticos de variedades indianas cultivadas de $C$. annuum, encontrou variantes para o número cromossômico $2 \mathrm{n}=24$. Das variedades analisadas três 
apresentaram $2 \mathrm{n}=36$ cromossomos, uma variedade $2 \mathrm{n}=48$ e cinco variedades $2 n=24$, confirmando o número básico do gênero $x=12$. $O$ autor conclui, portanto, que cada variedade apresenta sua própria particularidade na morfologia cromossômica indicando que as alterações cromossômicas estruturais têm importante papel na domesticação de variedades e evolução das espécies do gênero Capsicum.

C. campylopodium, C. rhomboideum (Humb \& Bonpb.) e alguns acessos de C. mirable Mart., apresentam $\mathrm{x}=13$, sendo $2 \mathrm{n}=26$ onde os cromossomos extras são pequenos e acrocêntricos (Pickersgill, 1991). Várias hipóteses, foram levantadas para explicar a origem dessas espécies com $x=13$. Moscone et al. (1993) ao investigar o padrão de bandamento-C em C. campylopodium $(\mathrm{x}=13)$ e C. pubescens $(\mathrm{x}=12)$ verificaram que o padrão de bandas-C era compativel entre as duas espécies, e sugeriram que os dois cromossomos acrocêntricos extras (cromossomos 12 e 13) de C. campylopodium podem ter se originado como resultado de uma fissão cêntrica (Robertsoniana) de um cromossomo grande metacêntrico de C. pubescens.

A análise cariotípica de espécies e variedades cultivadas e selvagens no gênero Capsicum tem mostrado uma grande similaridade entre os cariótipos da maioria das espécies, com cromossomos apresentando pequenas diferenças no tamanho, comprimento relativo e posição do centrômero (Carluccio e Saccardo, 1977; Limaye e Patil, 1989; Pickersgill, 1991; Moscone et al., 1990, 1993, 1995, 1996; Bertão, 1993).

Apesar desta similaridade entre os cariótipos são encontradas variações intra e interespecificas no gênero. A avaliação de parâmetros de morfologia cromossômica como tamanho absoluto, relação de braços, comprimento do lote haplóide, relação cromossomo maior/menor e indice de simetria $(\mathrm{TF} \%)$ das espécies cultivadas $C$. annuum, $C$. 
chinenese, $C$. frutescens, e $C$. baccatum e das espécies selvagens $C$. flexuosum, $C$. chacoense, $C$. parvifolium e $C$. praetermissum, permitiu a caracterização dos cariótipos em todas as espécies e variedades estudadas, especificamente a identificação de cada par cromossômico Bertão (1993).

No decorrer das últimas quatro décadas tem-se observado um crescente interesse em se definir parâmetros que possam auxiliar na caracterização morfológica e estrutural dos cromossomos de espécies do gênero Capsicum. Dessa forma, técnicas que promovam distinção crítica dos cromossomos, permitindo uma identificação mais precisa, é de relevãncia, podendo trazer grandes contribuições para estudos taxonômicos e de evolução cariotípica de famílias e gêneros.

Ao avaliar as contribuições dos diferentes estudos citogenéticos realizados no gênero Capsicum, Pickersgill (1991) concluiu que vários aspectos precisam ser melhor explorados. Dessa forma, as diferentes técnicas de bandamento apresentam-se como uma importante ferramenta em estudos citogenéticos, uma vez que, ao evidenciar a diferenciação longitudinal dos cromossomos, permite uma nítida identificação dos mesmos, contribuindo para uma melhor caracterização de espécies e cultivares e desta forma possibilitar um melhor entendimento da taxonomia e do processo evolutivo ocorrido no gênero.

\subsection{Bandamento cromossômico}

As técnicas de bandamento cromossômico evidenciam bandas que representam um tipo de organização do genoma dos eucariotos e 
refletem a diferenciação longitudinal existente nos cromossomos. Essas técnicas são aplicadas principalmente em cromossomos metafásicos.

Estas metodologias de bandamento foram inicialmente utilizadas em estudos de Citogenética Humana, onde se mostraram eficientes na detecção de alterações estruturais nos cromossomos tais como: deleçōes, duplicaçōes e inversōes, permitindo identificar com precisão qual a região do cromossomo envolvida. Em outras espécies, as técnicas de bandamento tem sido usadas para avaliar alteraçōes cromossômicas que se estabeleceram no cariótipo, bem como identificar em células híbridas os cromossomos de cada espécie parental. Em estudos de evolução, o bandamento tem possibilitado uma melhor avaliação das transformações que ocorreram em grupos de espécies próximas com cariótipos semelhantes.

Vários métodos de bandamento têm sido descritos na literatura, alguns usando corantes fluorescentes, especialmente a quinacrina que mostra fluorescência aumentada ou reduzida ao longo dos cromossomos.

A técnica de bandamento-C em cromossomos de plantas foi introduzida por Vosa e Marchi (1972ab). Este método derivou-se a partir de experimentos de hibridação in situ desenvolvidos com o objetivo de se localizar sequências de DNA altamente repetitivo em cromossomos de camundongos (Pardue \& Gall, 1970).

O bandamento-C revela padrōes de heterocromatina constitutiva das espécies. As bandas-C apresentam diversidade $\mathrm{e}$ variabilidade, e são encontradas em praticamente todas as espécies de eucariotos.

A introdução de técnicas de bandamento no estudo de citogenética de plantas tem se constituído em uma importante ferramenta para a identificação de alterações cromossômicas 
estruturais, bem como para auxiliar em estudos citotaxonômicos e na investigação da origem de plantas cultivadas (Vosa, 1989).

Embora as diferentes técnicas de bandamento apresentem-se como ferramentas importantes em estudos citogenéticos em plantas, na familia Solanaceae estas tem sido aplicadas em apenas alguns gêneros: Cestrum (Berg \& Greilhuber, 1992, 1993ab), Cyphomandra (Pringle, 1990), Hyoscyamus (Tyagi \& Gill, 1990), Nicotiana (Mouras, 1982; Mouras et al., 1986), Petunia (Dietrich et al., 1981; Wijsman et al., 1983), Solanum (Pijnacker \& Ferwerda, 1984) e Capsicum (Moscone et al., 1993, 1995, 1996).

Em Petunia hybrida, a técnica de bandamento-C associada à análise meiótica, evidenciou uma grande variação de heterocromatina entre as diferentes linhagens. Neste gênero, foi observado uma predominância de bandas distribuídas nas regiões proximais dos cromossomos, apresentando considerável variação no tamanho, intensidade de coloração e distribuição espacial dentro de cada grupo (Dietrich et al., 1981)

No gênero Solanum, a técnica de bandamento-C evidenciou três tipos de heterocromatina distribuídas entre os cromossomos: heterocromatina centromérica, telomérica e intersticial (Ramanna \& Wagenvoort, 1976; Pijnacker \& Ferwerda, 1984). A análise de cromossomos através do método de bandamento- $\mathrm{C}$, têm se mostrádo eficiente para detectar rearranjos estruturais.

Bandas teloméricas, intersticiais e centroméricas também ocorrem em Nicotiana tabacum (Mouras, 1982; Mouras et al., 1986). Este padrão de bandas também foi encontrado em Hyoscyamus muticus, onde doze pares de cromossomos mostraram bandas- $\mathrm{C}$ que diferem no tamanho, posição e intensidade. No gênero Hyoscyamus a metodologia de bandamento-C permitiu a identificação dos 14 pares de 
cromossomos. Neste gênero, esta técnica além de permitir a identificação dos cromossomos poderá ser importante na identificação de aneuplóides de H. muticus (Tyagi \& Gill, 1990).

Entre todas as Solanáceas, o gênero Cestrum foi o mais estudado pelas diferentes técnicas de bandamento. As espécies de $C$. strigillatum, C. fasciculatum, C. elegans, C. aurantiacum e C. parqui, fazem parte de um grupo de plantas que apresentam certos segmentos cromossômicos que apresentam baixa condensação cromossômica induzida por tratamento a frio, sendo um fenômeno raro em plantas. Estas regiões foram encontradas em onze gêneros de monocotiledôneas e três de dicotiledôneas. As causas moleculares da baixa condensação destas regiões não são ainda conhecidas (Berg \& Greilhuber, 1992, 1993ab).

As espécies de Cestrum avaliadas por diferentes técnicas de bandamento cromossômico, revelaram similaridades quanto às caracteristicas qualitativas da heterocromatina e também quanto à estrutura cariotipica. Neste estudo foram identificados quatro tipos diferentes de heterocromatina: segmentos cromossômicos que apresentam baixa condensação induzida por baixas temperaturas, as regiões organizadora de nucléolos, pequenas regiões ricas em $\mathrm{G}+\mathrm{C}$ que coram positivamente com cromomicina $\mathrm{A}_{3}$, e heterocromatina com fluorescência indiferenciada. Este último tipo de heterocromatina não mostrou fluorescência, com nenhum dos fluorocromos base-especificos utilizados, tais como cromomicina Аз (CMA) e 4'-6-diamino-2-fenilindol (DAPI), não sendo evidenciadas regiões ricas em $\mathrm{G}+\mathrm{C}$ ou em $\mathrm{A}+\mathrm{T}$. A identificação destes diferentes tipos de heterocromatina foi possivel através de tratamento com baixas temperaturas, bandamento-C, bandamento- $\mathrm{N}$, coloração com nitrato de prata e fluorocromos baseespecificos (Berg \& Greilhuber, 1992, 1993ab). 
As espécies de Cestrum avaliadas apresentam cariótipos similares basicamente com sete cromossomos metacêntricos e um subtelocêntrico. Significativas variações interespecificas e polimorfismos decorrentes da heterocromatina constitutiva foram encontrados (Berg \& Greilhuber, 1992, 1993ab).

As regiões que apresentam baixa condensação cromossômica induzida por tratamento a frio são características importantes de todas as espécies de Cestrum estudadas. A técnica de bandamento-C revelou que estas regiões correspondem a heterocromatina constitutiva $\mathrm{e}$ mostram variações entre espécies, bem como sugere homologia entre os cariótipos. A análise destas regiões com o uso de fluorocromos baseespecificos revelou que este tipo de heterocromatina é rica em bases $\mathrm{A}+\mathrm{T}$ (Berg \& Greilhuber, 1992, 1993ab). Por outro lado, em Paris polyphilla (Filion \& Vosa, 1980) e Tulbaghia leucantha (Vosa \& Marchi, 1972ab) foi observado que as regiōes que apresentam baixa condensação cromossômica induzida por tratamento a frio são ricas em bases $\mathrm{G}+\mathrm{C}$.

No gênero Cestrum, as regiōes que apresentam baixa condensação cromossômica induzida por tratamento a frio sugerem uma homologia filogenética para este grupo, uma vez que estas são desconhecidas em outras espécies de Solanáceas. A análise citoquímica da heterocromatina da RON, mostrou que estas regiões são ricas em bases $\mathrm{G}+\mathrm{C}$ como é comum em plantas (Sinclair \& Brown, 1971), sugerindo que não há homologia filogenética dentro do grupo.

A heterogeneidade de bandas heterocromáticas, como encontrado no gênero Cestrum, foram evidenciadas desde o início da aplicação de técnicas de bandamento- $C$, quando foram encontradas quatro tipos diferentes de segmentos heterocromáticos, diferenciados pela resposta a coloração com quinacrina e pelo uso de baixa temperatura em um mesmo organismo. Em Scilla sibirica, há três tipos 
de segmentos heterocromáticos (distal, intercalar e centromérico), e através de coloração com quinacrina, observam-se dois tipos de heterocromatina: com fluorescência reduzida (distal e intercalar) e com fluorescência intensa (centromérica). Esses segmentos são positivamente evidenciados pelo método de bandamento-C (Vosa, 1985).

$\mathrm{O}$ uso da metodologia de bandamento-C em seis espécies diplóides de Capsicum, revelou um padrão de bandas caracterizado pelo presença de bandas teloméricas assimetricamente distribuídas, bem como a presença de bandas centroméricas na maioria dos cromossomos. A avaliação dos cariótipos corados por esta técnica revelou diferenças significativas quanto ao padrão de distribuição e conteúdo de heterocromatina entre as espécies estudadas. Com base nessas informações (Moscone et al., 1993) classificaram estas espécies em dois grupos. No grupo I são incluídas as espécies que apresentam menor quantidade de heterocromatina ( $C$. chacoense, C. parvifolium, $C$. annuum, C. baccatum var. pendulum). Este grupo apresenta a heterocromatina distribuída em pequenas bandas teloméricas $e$ centroméricas presentes na maioria dos cromossomos. Bandas intercalares são ausentes ou escassas.

As espécies do grupo II apresentam um alto teor de heterocromatina (C. pubescens, C. campylopodim), distribuídas em grandes blocos heterocromáticos nas regiões teloméricas e algumas bandas intercalares. Apesar da grande variação com relação à quantidade de heterocromatina entre as espécies de Capsicum, um padrão básico de distribuição de bandas-C é mantido. A grande variação refere-se às bandas teloméricas (incluindo o satélite), as quais correspondem à maior proporção de heterocromatina do grupo. As bandas intercalares são escassas e encontram-se desigualmente distribuídas entre os braços cromossômicos. 
O bandamento-C revelou em Capsicum, poucos casos de heteromorfismo entre cromossomos homólogos. Isto indica um baixo grau de heterozigosidade estrutural e sugere falta de hibridação, bem como baixa proporção de recombinação (Moscone et al., 1993). Estes dados tem boa concordância com os dados de isoenzimas obtidos no gênero por Jensen et al. (1979).

A técnica de coloração com nitrato de prata permite a identificação das regiões organizadoras de nucléolo nas constrições secundárias dos cromossomos satelitados de plantas e animais. Esta técnica tem sido usada para detectar sítios de genes rDNA ativos, uma vez que somente RONs funcionalmente ativas durante a intérfase que precedeu a mitose que se observa, podem ser visualizados pela coloração com nitrato de prata. Em eucariotos os genes ribossômicos (rRNA; 18S-5.8S-26S) são organizados em sequências repetidas em tandem, localizados em alguns poucos sitios cromossômicos. A coloração com nitrato de prata, tem sido muito usada para analisar atividade nucleolar e competição em plantas diplóides, poliplóides e híbridos interespecíficos, e também na análise transcripcional de cromossomos plumulados (Verma, 1995; Friebe et al., 1996).

Em Solanáceas, o método de coloração com nitrato de prata que demonstra a atividade de sítios de genes rDNA, foi utilizado nos gêneros Solanum (Pijnacker e Ferwerda, 1984, 1991), Cestrum (Berg \& Greilhuber, 1992, 1993ab) e Capsicum (Moscone et al., 1995)

Em Capsicum os dados disponiveis na literatura com referência à atividade nucleolar, são os resultados da análise das constrições secundárias observadas em cromossomos satelitados e convencionalmente corados (Pickersgill, 1971, 1977; Limaye \& Patil, 1989; Moscone et al., 1990; Bertão, 1993). Estes dados foram posteriormente confirmados através da avaliação de metáfases mitóticas 
coradas pelo método de coloração com nitrato de prata em oito espécies diplóides de Capsicum com $2 n=24$ e uma espécie com $2 n=26$, onde foi evidenciado a presença de no minimo um e no máximo quatro RONs por complemento haplóide (Moscone et al., 1995).

Divergências quanto ao número de RONs presentes na metáfase em relação ao número de nucléolos no núcleo interfásico em espécies de Capsicum (Moscone et al., 1995), pode ocorrer devido ao processo de fusão tardia (Lacadena et al., 1984). Por outro lado, um número menor RONs em relação ao número de nucléolos, é atribuído a uma baixa atividade transcripcional de pequenos sitios de rDNA, os quais não são identificados pela coloração com nitrato de prata, podendo no entanto produzir um micronucléolo interfásico (Sato et al., 1980).

Entre os gêneros de Solanáceas avaliados pela técnica de coloração com prata, uma situação curiosa ocorre em espécies do gênero Cestrum, onde as RONs não são visiveis em metáfases mitóticas. Nestas espécies, a coloração com nitrato de prata desses sítios ocorre na intérfase, prófase ou na prometáfase, onde podem ser identificados (Berg \& Greilhuber, 1992, 1993ab).

A presença de alto número de RONs por complemento haplóide (quatro), como encontrado para a variedade EAM 205 de C. baccatum, tem sido citada na literatura em trabalhos de hibridação in situ (Leitch \& Heslop-Harrison, 1992; Maluszysca \& Heslop-Harrison, 1993; Hanson et al., 1996; Linares et al., 1996; Xu \& Earle, 1996; Katsiotis et al., 1997).

A técnica de hibridação in situ permite a identificação de outros sítios de genes rDNA, além dos encontrados nas constricções secundárias de cromossomos satelitados. A aplicação desta técnica em diferentes cultivares da espécie $C$. chinense evidenciou quatro regiões de 
braço longo de um par metacêntrico (Tanksley et al., 1988), enquanto que o método de coloração com nitrato de prata evidenciou apenas as RONs do par satelitado (Moscone et al., 1995).

Um outro tipo de abordagem no estudo da heterocromatina de diferentes espécies de plantas cultivadas e selvagens, têm consistido na coloração de cromossomos por fluorocromos base-específicos, que revela de um modo geral, os subconjuntos de heterocromatina constitutiva ricos em $A+T$ (quinacrina e $\mathrm{DAPI}$ ) ou ricas em $\mathrm{G}+\mathrm{C}$ (cromomicina $\mathrm{A} 3 \mathrm{e}$ mitramicina).

A aplicação de fluorocromos base-especificos para caracterizar citoquimicamente a heterocromatina da RON em espécies de Capsicum, revelou que estas são ricas em bases $\mathrm{G}+\mathrm{C}$, como é comum em plantas (Sinclair \& Brown, 1981). O estudo das RONs através do método de coloração com prata em grupos de plantas selvagens e cultivadas se reveste de importância, uma vez que pode trazer grandes contribuições para os estudos sistemáticos e filogenéticos.

O uso de fluorocromos (cromomicina A3, DAPI) para uma análise mais detalhada de cariótipos de cinco espécies cultivadas de Capsicum, (C. annuum, C. frutescens, C. chinense, C. baccatum e C. pubescens), revelou um grande número de bandas fluorescentes terminais, raras bandas intercalares e bandas centroméricas indefinidas. Em todas as espécies investigadas, houve uma predominância de regiões positivas para $\mathrm{G}+\mathrm{C}$, evidenciadas pela cromomicina А3. Somente C. pubescens mostrou uma banda terminal positiva para A+T evidenciada pelo DAPI, no braço longo do cromossomo 10, que corresponde à única região rica em $\mathrm{A}+\mathrm{T}$ encontrada em todas as espécies cultivadas de Capsicum analisadas (Moscone et al., 1996).

Os cariótipos corados pelo método de bandamento-C, mostraram boa correspondência com o padrão de bandas apresentado 
pelos cariótipos corados com fluorocromos base-especificos, principalmente com relação às bandas teloméricas, divergindo quanto a presença de bandas centroméricas uma vez que estas são bem marcadas pelo bandamento- $\mathrm{C}$, e ausentes ou fracamente marcadas após coloração com fluorocromos base-específicos (Moscone et al., 1996). A falta de discriminação de determinadas regiōes de heterocromatina através do uso de fluorocromos base-especificos também é encontrada em espécies do gênero Cestrum, onde "clusters" intercalares apresentam fluorescência indiferenciada com cromomicina A3 e DAPI, embora sejam banda-C positiva. Esta indiferença a fluorocromos base-especificos para $A+T$ ou $G+C$, pode significar que estes subconjuntos de heterocromatina constitutiva não são particularmente ricos em $A+T$ ou $G+C$, ocorrendo intercalação destes pares de bases.

As diferenças encontradas nos cariótipos das espécies de Capsicum corados por fluorocromos base-especificos revelaram diferenças no conteúdo, distribuição e tipo de heterocromatina como já evidenciado pela metodologia de bandamento-C. Estas diferenças podem significar uma divergência evolucionária intraespecifica para o gênero (Moscone et al., 1996).

A introdução de técnicas de bandamento em estudos de cromossomos de plantas, tem ajudado a elucidar vários problemas da estrutura dos cromossomos e mostrado ser uma importante ferramenta, para a identificação de alterações. Estas técnicas também são importantes para esclarecer problemas de ordem citotaxonômica, de sistemática e estudos sobre a origem de plantas cultivadas, entre outros.

Dentro destas perspectivas um trabalho envolvendo técnicas de bandamento cromossômico para avaliar o cariótipo de espécies e variedades selvagens e cultivadas do gênero Capsicum revestem-se de 
importância, uma vez que os dados obtidos possibilitarão um melhor entendimento da evolução cariotípica, bem como contribuirão para o estudo taxonômico do gênero. 


\section{MATERIAL E MÉTODOS}

\subsection{Material}

Foram avaliadas quatro espécies pertencentes ao gênero Capsicum, sendo três espécies domesticadas e uma espécie selvagem, as quais encontram-se relacionadas na Tabela 1.

As sementes usadas foram cedidas pelo Prof. Dr. Cyro Paulino da Costa ESALQ/USP, Prof. Dr. Walter Casali da Universidade Federal de Viçosa - MG e Dr. Piero Belleti do Institute of Breeding of Plant and Seed Production, Turin - Itália.

As espécies domesticadas $C$. chinense Jacq. e $C$. baccatum L. e a selvagem C. praetermissum Heiser \& Smith, foram identificadas e classificadas através da chave de classificação proposta por Pickersgill (comunicação pessoal à Aguiar-Perecin, 1985).

\subsection{Métodos}

\subsubsection{Germinação de sementes}

Para evitar possivel contaminação por fungos e também promover a quebra de dormência, as sementes foram previamente 
tratadas com uma solução de nitrato de potássio a $1 \%$ durante 10 minutos.

As sementes foram germinadas em recipiente contendo Sphagnum umedecido, em banho-maria com temperatura controlada de 28 a $30^{\circ} \mathrm{C}$.

\subsubsection{Obtenção de metáfases mitóticas}

As raizes com aproximadamente um centimetro de comprimento foram coletadas e em seguida submetidas a um prétratamento combinando 8-hidroxiquinolina com cicloheximida

O pré-tratamento aplicado às raizes de Capsicum, foi estabelecido a partir de alguns testes:

a) 8-hidroxiquinolina $300 \mathrm{ppm}$ por um periodo de 2:15 a 2:45 horas;

b) 8-hidroxiquinolina $300 \mathrm{ppm}$ combinada com cicloheximida $25 \mathrm{ppm}$ por um periodo de 2:15 a 2:45 horas;

c) 8-hidroxiquinolina $300 \mathrm{ppm}$ combinada com cicloheximida $12,5 \mathrm{ppm}$ por um periodo de 2:15 a 2:45 horas.

Após o pré-tratamento as raizes foram fixadas em etanol:ácido acético (3:1) por 12 horas a temperatura ambiente $\left(25-28^{\circ} \mathrm{C}\right)$ e posteriormente guardadas a $4^{\circ} \mathrm{C}$.

\subsubsection{Bandamento-C}

O procedimento adotado para obtenção de bandas- $C$ seguiu em linhas gerais as técnicas descritas por Aguiar-Perecin (1985) e Schwarzacher et al. (1980) com algumas modificações. 
Tabela 1. Lista de espécies de Capsicum analisadas, nome científico, número da coleção, variedade, procedência e número de cromossomos.

\begin{tabular}{lllll}
\hline \multicolumn{1}{c}{ Espécie } & $\begin{array}{c}\text { Número * } \\
\text { da coleção }\end{array}$ & \multicolumn{1}{c}{ Variedade } & \multicolumn{1}{c}{ Procedência } & 2n \\
\hline C. annuum L. & 1002 & $\begin{array}{l}\text { Calahora } \\
\text { "Pepperoncini" }\end{array}$ & México & 24 \\
C. chinense Jacq. & 2013 & Pimenta de bode & $\begin{array}{l}\text { Brasil, } \\
\text { Recife-PE }\end{array}$ & 24 \\
C. baccatum L. & 435 & & $\begin{array}{l}\text { Brasil, } \\
\text { Mogi Guaçu-SP }\end{array}$ & 24 \\
& 530 & Yerba Mala & Bolivia & 24 \\
& 2042 & Pimenta Pará & $\begin{array}{l}\text { Brasil, } \\
\text { Santarém-PA }\end{array}$ & 24 \\
& & & Brasil, & 24 \\
C. praetrmissum & BGH 6703 & Pimenta cumari & Viçosa-MG & \\
Heiser \& Smith & & & &
\end{tabular}

* Departamento de Genética ESALQ/USP 
Inicialmente foram realizados alguns testes variando-se a concentração, a temperatura e o tempo de tratamento no hidróxido de bário. Testes variando o tempo de tratamento na solução salina ( $2 x S S C)$ por um periodo de 1:00 a 1:30 horas também foram realizados.

As raizes mantidas em fixador e guardadas na geladeira foram submetidas às seguintes etapas:

- Maceração em ácido acético a $45 \%$, por 10 minutos seguida de esmagamento e observação das preparações citológicas em microscópio de contraste de fase;

- Separação das lâminas e laminulas em ácido acético a 45\% e posterior secagem à temperatura ambiente;

- Conservação das preparações em etanol absoluto a $4^{\circ} \mathrm{C}$, por no minimo 48 horas.

Para procedimento de bandamento- $\mathrm{C}$ as lâminas foram secas à temperatura ambiente. Após a secagem, as preparações cromossômicas foram tratadas com ácido acético a $45 \%$ por 10 minutos a $60^{\circ} \mathrm{C}$. Este tratamento foi interrompido com água corrente e em seguida as lâminas foram lavadas com água deionizada.

- Após secagem à temperatura ambiente, as preparações cromossômicas foram tratadas com solução de bário a $5 \%$ (filtrado) a $37^{\circ} \mathrm{C}$ por 20 minutos e lavadas com água deionizada por 2 vezes. Em seguida, as mesmas foram transferidas para uma solução salina 2xSSC (cloreto de sódio 0,3 $\mathrm{M}+$ citrato de sódio $0,03 \mathrm{M}, \mathrm{pH} 7,0$ ) a $60^{\circ} \mathrm{C}$ por um periodo de 60 minutos e lavadas em água deionizada, e submetidas a uma série de álcoois a $70 \%, 95 \%$ e absoluto. Após nova secagem à temperatura ambiente, as preparações cromossômicas foram então coradas usando-se uma solução de Giemsa a 1\% (solução estoque R66 da Gurr) preparada em tampão fosfato Gurr pH 6,8. O tempo de coloração foi testado em intervalos de 2 a 10 minutos. As 
lâminas foram então lavadas em água deionizada e, após secagem à temperatura ambiente, foram montadas em bálsamo do Canadá.

\subsubsection{Coloração com nitrato de prata}

As raizes após serem submetidas ao pré-tratamento, foram mantidas no fixador e guardadas a $4^{\circ} \mathrm{C}$ durante no máximo uma semana até a preparação das lâminas.

Para evidenciar as RONs foi seguido o método de Howell \& Black (1980), com algumas modificações, consistindo das seguintes etapas:

- Esmagamento da ponta de raiz em ácido acético a $45 \%$ e observação em microscópio de contraste de fase;

- Remoção da lamínula em ácido acético a $45 \%$ e secagem da lâmina à temperatura ambiente;

- Coloração do material foi realizada adicionando-se sobre a lâmina uma gota de gelatina $2 \%$ (preparada com $0,5 \mathrm{ml}$ de ácido fórmico puro) e duas gotas de $\mathrm{AgNO}_{3}$ a $50 \%$ (solução aquosa). Misturou-se levemente as soluções balançando a lâmina de um lado para outro e cobriu-se com uma laminula.

Durante a coloração a lâmina foi mantida em câmara úmida (placa de Petri forrada com papel de filtro umedecido) em banho-maria a $60^{\circ} \mathrm{C}$ por um periodo de 5 a 10 minutos. O tempo ideal de coloração foi definido através de monitorização ao microscópio óptico.

A laminula foi removida em água deionizada e após secagem, montada em bálsamo do Canadá. 


\subsubsection{Bandamento-Q}

Para o bandamento-Q as raizes após serem pré-tratadas foram mantidas no fixador e mantidas a $4^{\circ} \mathrm{C}$ até a preparação das lâminas.

Para obtenção de bandas-Q, seguiu-se a metodologia adotada por Vosa (1970), consistindo das seguintes etapas:

- Esmagamento da ponta de raiz em ácido acético a $45 \%$ e observação em microscópio de contraste de fase;

- Remoção da lamínula em ácido acético a $45 \%$ e posterior secagem a temperatura ambiente;

- Conservação das preparações em etanol absoluto a $4^{\circ} \mathrm{C}$.

As preparações cromossômicas foram secas à temperatura ambiente e em seguida coradas com uma solução aquosa de quinacrina $0,5 \%$ durante 10 a 20 minutos no escuro.

A remoção da laminula foi feita em água deionizada e após secagem, montada com uma gota de água deionizada e vedada com uma cola de borracha.

\subsection{Análise citológica}

As melhores preparações coradas pelos diferentes métodos de bandamento foram fotografadas em fotomicroscópio Zeiss. O filme utilizado foi Agfa Copex Pan A .H. U. TRI 13 (asa 32). Para as cópias fotográficas utilizou-se o papel MULTIGRADE IV, da ILFORD. As preparações citológicas coradas pelo nitrato de prata foram fotografadas com filme Kodak Gold (asa 100). 
Os valores obtidos permitiu o estabelecimento dos parâmetros, tais como: comprimento absoluto (em micrômetro), relação de braços e comprimento relativo, para identificação dos cromossomos.

Os valores de relação de braços e comprimento relativo foram calculados de acordo com a metodologia adotada por Aguiar-Perecin (1985) e Aguiar e Vosa (1985), como segue:

$$
\text { Relação de braços (RB) = } \frac{\text { braço maior }}{- \text { braço menor }^{-}}
$$

Para cada metáfase analisada foi determinada a média de cada relação de braço dos dois elementos de cada par de homólogos.

O comprimento relativo foi calculado em termos de percentagem do lote haplóide.

Comprimento relativo $(\mathrm{CR})=\frac{\text { comp. absoluto }}{\text { comp. do lote haplóide }}$

O tamanho da banda-C foi calculado pela diferença entre os valores da distância entre o centrômero e o início da banda e da distância entre centrômero e o final da banda.

Com base nesses dados e no padrão de bandas, foram construídos os cariótipos e ideogramas dos genótipos analisados. 


\section{RESULTADOS E DISCUSSÃO}

\subsection{Bandamento-C}

Vários testes foram realizados visando o estabelecimento de uma metodologia de bandamento-C para o gênero Capsicum, uma vez que na literatura existem poucos trabalhos referentes a aplicação desta metodologia no gênero (Moscone et al., 1993).

Para obtenção de metáfases com cromossomos bem espalhados e com boa morfologia foram testados pré-tratamentos das raizes com hidroxiquinolina $(300 \mathrm{ppm})$ associada à cicloheximida $(12,5 \mathrm{e}$ 25 ppm) por 2:00-2:45 horas. A melhor combinação foi hidroxiquinolina $300 \mathrm{ppm}+$ cicloheximida $12,5 \mathrm{ppm}$ por $2: 15$ horas a $28^{\circ} \mathrm{C}$.

Visando-se a obtenção de melhores preparações cromossômicas as raizes foram submetidas a tratamentos com solução enzimática (pectinase $1 \%$ mais celulase $1 \%$ ) a $37^{\circ} \mathrm{C}$ variando o tempo (15-30 minutos), como sugerido por Moscone et al. (1993). Após o tratamento enzimático, o material cromossômico submetido à metodologia de bandamento-C corava-se uniformemente, não mostrando a diferenciação de bandas-C. Portanto, nas preparações seguintes não se utilizou tratamento enzimático.

Estabelecido o pré-tratamento, iniciou-se os testes de bandamento-C seguindo a metodologia descrita por Aguiar-Perecin (1985) para milho, variando-se o tempo de incubação em bário (5-25 
minutos) e a temperatura (ambiente e $37^{\circ} \mathrm{C}$ ). Entretanto, não se observaram bandas-C. Foi testada também a metodologia utilizada em Capsicum por Moscone (1993) e estabelecida por Schwarzacher et al. (1980) para análise de cariótipos de orquídea. A reprodução dos resultados obtidos por Moscone (1993) utilizando-se esta técnica não foi possivel. A partir de então foi realizada uma série de testes combinando as duas metodologias citadas acima.

As primeiras observações de bandas-C ocorreram quando as preparações cromossômicas foram tratadas com ácido acético a $45 \%$ a $60^{\circ} \mathrm{C}$ por 15 minutos, antes da incubação em bário $5 \%$ a $25-37^{\circ} \mathrm{C}$. Embora tenham sido observadas bandas-C a morfologia dos cromossomos ficou muito alterada (aspecto "ghost") devido à desnaturação excessiva.

Novos testes foram realizados reduzindo-se o tempo de tratamento em ácido acético a $45 \%$ para 5-15 minutos à temperatura ambiente ou $60^{\circ} \mathrm{C}$, bem como variando-se a concentração na solução de bário (3-6\%), o tempo de incubação (5-25 minutos) e a temperatura (ambiente e $37^{\circ} \mathrm{C}$ ), e também o tempo para coloração com Giemsa a $1 \%$ (2-90 minutos). A combinação de tratamento ácido por 10 minutos a $60^{\circ} \mathrm{C}$, incubação em bário a $5 \%$ filtrado por 20 minutos a $37^{\circ} \mathrm{C}$ e coloração com Giemsa por 10 minutos permitiu a visualização de bandas-C e preservação da morfologia dos cromossomos.

Os resultados obtidos com a aplicação desta metodologia de bandamento-C permitiram estabelecer um padrão de distribuição de bandas nas espécies avaliadas.

Através da análise dos valores de comprimento absoluto, relação de braços e comprimento relativo dos cromossomos corados pelo bandamento-C (Tabela 2) foi possivel identificar os pares de cromossomos (Figura 1) e a elaboração de ideogramas (Figura 2) com o 
padrão de distribuição de heterocromatina constitutiva em espécies e variedades cultivadas e selvagem.

Ao se comparar os valores referentes ao comprimento absoluto, relação de braços e comprimento relativo de metáfases somáticas coradas pelo bandamento-C e pelo método de Feulgen (Bertão, 1993), como mostrado na Tabela 2, algumas variaçōes nos valores foram observadas. Alguns fatores devem ser considerados ao se avaliar esta variação:

a) O pré-tratamento usado por Bertão (1993), para obtenção de metáfases mitóticas foi 8-hidroxiquinolina $(0,002 \mathrm{M})$ por duas horas e meia a temperatura de $25-28^{\circ} \mathrm{C}$, sendo que no presente trabalho as metáfases mitóticas foram obtidas através do pré-tratamento combinando hidroxiquinolina $300 \mathrm{ppm}$ mais cicloheximida $12,5 \mathrm{ppm}$ por duas horas e quinze minutos a temperatura de $25-28^{\circ} \mathrm{C}$. Estes tipos diferentes de tratamento das raizes podem ter condicionado pequenas diferenças no tamanho dos cromossomos.

b) As medidas de Bertão (1993), foram obtidas através da avaliação de metáfases coradas pelo método de Feulgen, e a do presente trabalho pela metodologia de bandamento-C. Nesta metodologia, os cromossomos são submetidos à desnaturação com hidróxido de bário e renaturação em solução salina a temperaturas elevadas $\left(60^{\circ} \mathrm{C}\right)$. Este processo de desnaturação e renaturação dos cromossomos podem promover alterações em seu comprimento absoluto ou talvez as metáfases com bandas mais nitidas medidas eram menos condensadas que os materiais analisados por Bertão (1993). Estes dados podem ser observados na Tabela 2 , onde os valores de comprimento absoluto das metáfases avaliadas pelo método de bandamento-C são maiores quando comparadas com os valores do comprimento absoluto das metáfases coradas pelo método de Feulgen. 


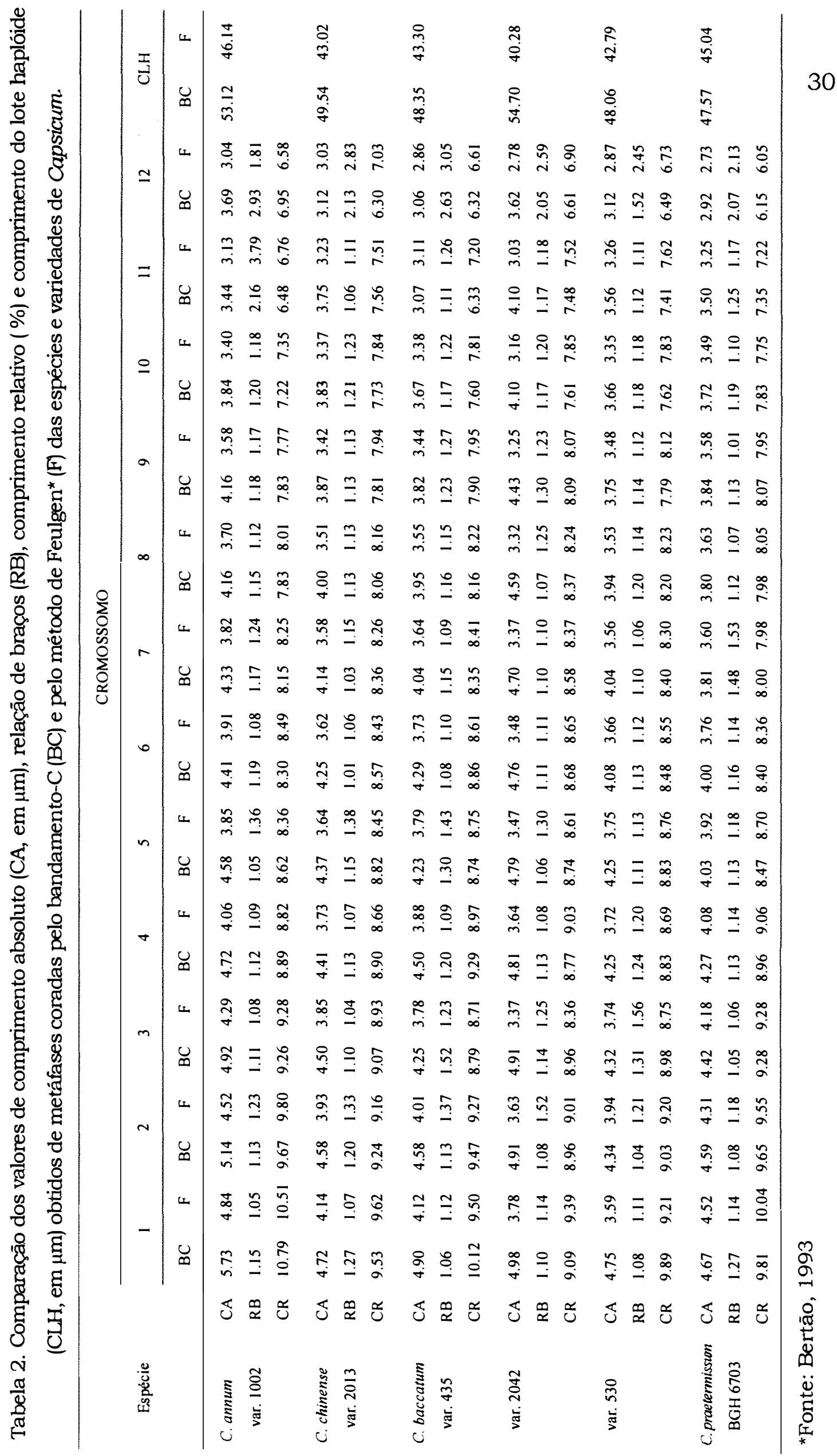




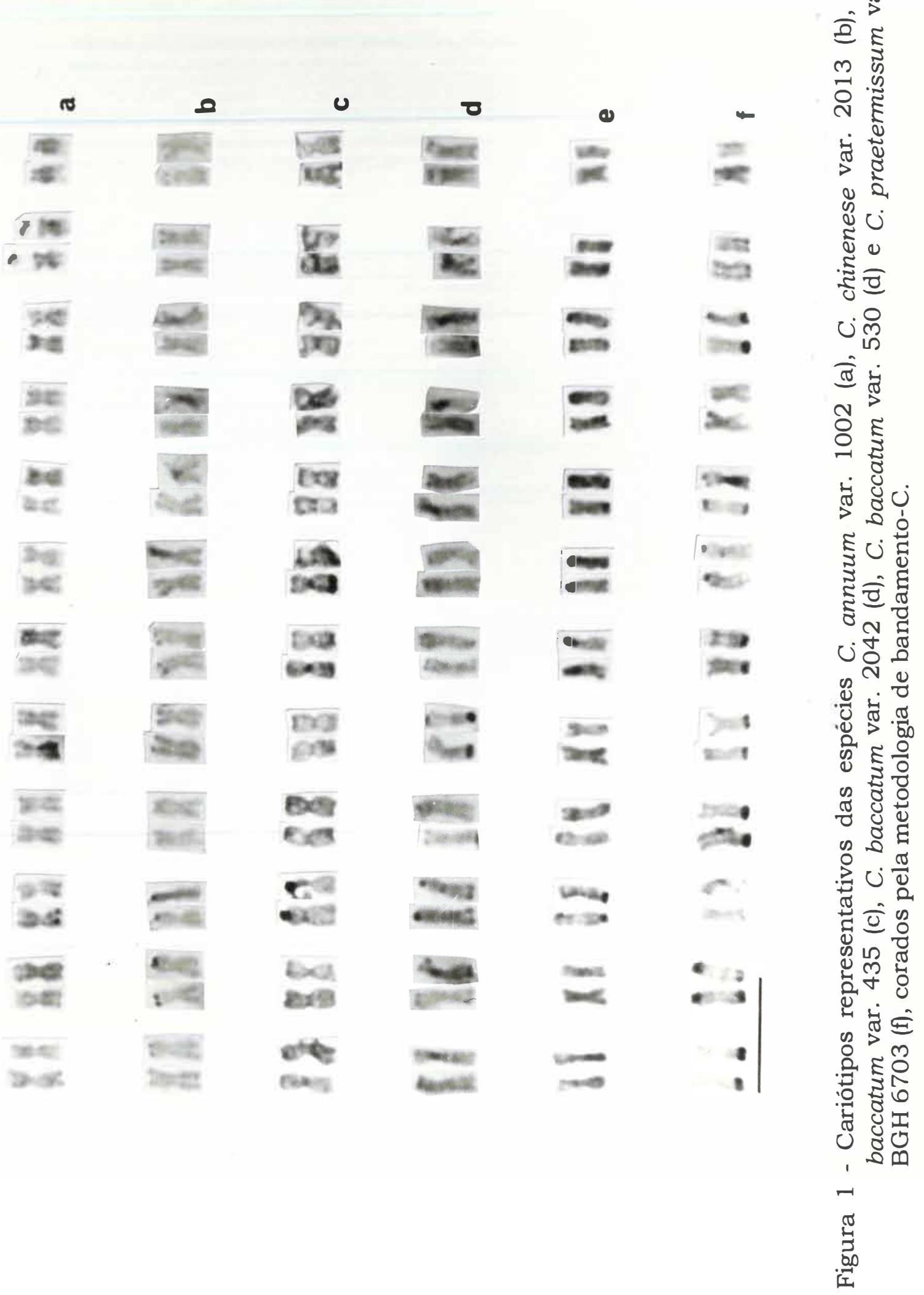




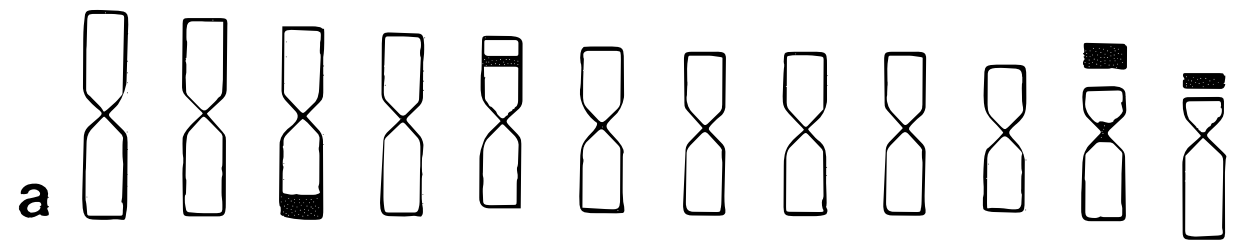

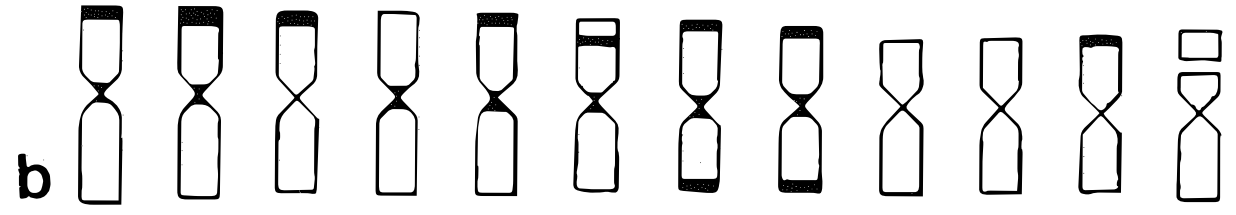

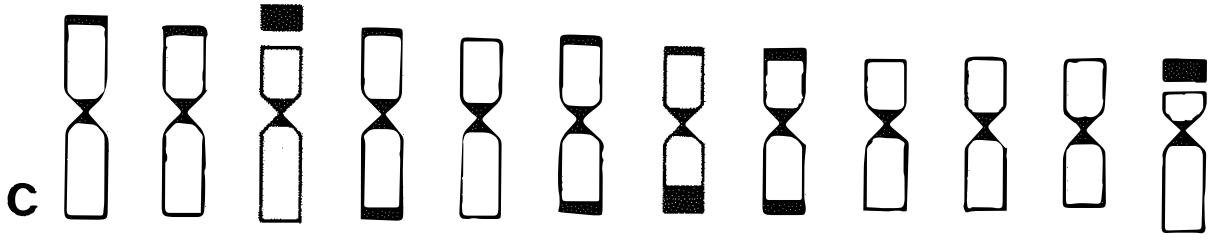

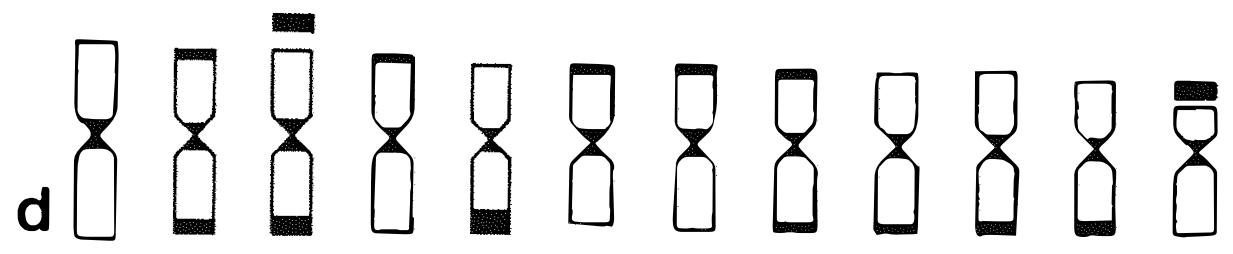

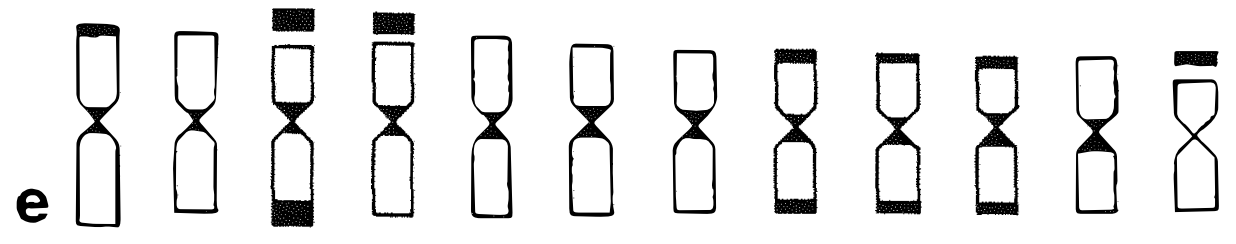

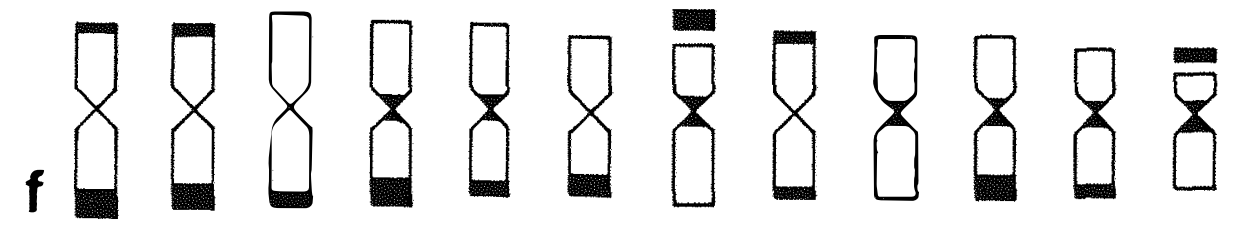

Figura 2 - Ideograma representativo das espécies C. annuum var. 1002 (a), C. chinenese var. 2013 (b), C. baccatum var. 435 (c), C. baccatum var. 2042 (d), C. baccatum var. 530 (d) e $C$. praetermissum var. BGH 6703 (f) 
Em Capsicum, os dados comparando cariótipos corados com fluorocromos base-específicos e cariótipos corados convencionalmente (com diferentes preparações) revelaram diferenças de quase um terço no comprimento do cariótipo (Moscone et al., 1996), entretanto, a comparação entre cariótipos corados pela metodologia de bandamento-C e por coloração convencional não foram relatados.

\subsubsection{Espécies cultivadas}

C. annuum var 1002 - Esta espécie apresenta um cariótipo constituído de 11 pares de cromossomos metacêntricos e um par submetacêntrico (Bertão, 1993). Foi observado um baixo teor de heterocromatina constitutiva distribuída entre seus cromossomos, representada por uma pequena banda-C telomérica no braço longo do cromossomo 3 e uma banda intercalar no braço curto do cromossomo 5 . $\mathrm{O}$ satélite situado no cromossomo 11 apresenta uma banda-C fortemente corada (Figuras la e 2a).

O padrão de distribuição de heterocromatina constitutiva nesta espécie discorda quanto ao padrão apresentado por Moscone et al. (1993) onde pequenas bandas-C terminais foram observadas na maioria dos cromossomos e os pares 9 e 11 apresentam bandas intercalares. Há concordância quanto a presença de banda-C no satélite do par 11 .

Os dados de bandamento-C obtidos mostram boa correspondência com o padrão de bandamento fluorescente do citotipo 2 da mesma espécie, analisada por Moscone et al. (1996), onde foi observada uma banda grande no satélite do par 11 e apenas uma banda intercalar no braço curto do cromossomo 6 . 
C. chinense var. 2013 - Esta variedade apresenta 11 pares de cromossomos metacêntricos e um par de cromossomos submetacêntricos satelitado (Bertão \& Aguiar-Perecin, 1991; Bertão, 1993). A aplicação da técnica de bandamento-C revelou uma baixa quantidade de heterocromatina distribuída nas regiões teloméricas dos cromossomos, preferencialmente nos braços curtos dos cromossomos 1 , $2,3,5$ e 11 , e em ambos os braços dos pares 7 e 8 . A banda-C encontrada no braço curto dos cromossomos 6 é subtelomérica (Figuras $1 \mathrm{~b}$ e $2 \mathrm{~b}$ ). Estes dados apresentam concordância quanto ao padrão de bandas-C encontrado por Bertão (1993) em um estudo preliminar. O único dado discordante refere-se a ausência de bandas no satélite grande do par 12.

As possiveis causas dessa discordância, podem referir-se ao fato de que a metodologia de bandamento-C utilizada por Bertão (1993) promovia uma fraca desnaturação dos cromossomos, enquanto que a metodologia estabelecida no presente estudo promove uma desnaturação mais expressiva e como consequência não se tem a marcação do macrosatélite do par 12, que poderá corresponder a um tipo de heterocromatina diferente daquele encontrado nas regiões teloméricas.

A ocorrência de diferentes tipos de heterocromatina nesta espécie poderá ser avaliada em estudos futuros através da utilização de fluorocromos base-especificos.

Moscone et al. (1996) avaliando duas linhagens EAM199 (citotipo 1) e EAM 201 (citotipo 2) desta espécie, relataram a presença de bandas teloméricas em dois pares de cromossomos, uma banda no braço curto do cromossomo 1 e outra no braço longo do cromossomo 8 , e no citotipo 2 foi observada também a presença de uma banda telomérica pequena no braço curto do cromossomo 2. Em ambos os 
citotipos o cromossomo 6 apresentou uma pequena banda intercalar no braço curto. Estes dados mostram certa concordância com os dados obtidos no presente trabalho, divergindo quanto ao número de pares $\mathrm{e}$ quais os pares cromossômicos que apresentam bandas, há no entanto, concordância quanto à presença de uma banda subterminal presente no braço curto do cromossomo 6. Moscone et al. (1996) não fazem referência quanto a presença de banda-C no satélite do par número 12 , embora este mostre fluorescência intensa quando corado com cromomicina $\mathrm{A}_{3}$, revelando que a heterocromatina presente no satélite é rica em bases $\mathrm{G}+\mathrm{C}$.

No gênero Cestrum (Solanaceae), o uso de diferentes metodologias de coloração (tratamento a frio, bandamento-C, bandamento-N, técnica de coloração pelo nitrato de prata e uso de fluorocromos base-especificos) permitiu a identificação de quatro diferentes tipos de heterocromatina neste gênero (Berg e Greilhuber, 1992, 1993ab).

Em Capsicum a única tentativa de se evidenciar heterocromatina através da técnica de baixa temperatura foi feita por Shopova (1966). Foi constatada a presença de grandes blocos de heterocromatina próximos ao centrômero nas espécies $C$. annuum, $C$. pubescens e C. frutescens, sendo mais pronunciadas em C. pubescens onde foi também encontrada heterocromatina nas regiões teloméricas.

A análise de cromossomos das espécies $C$. annuum e $C$. pubescens corados através das metodologias de bandamento-C e fluorescente (Moscone et al., 1993, 1996), não confirmaram a presença dessa heterocromatina proximal, citada por Shopova (1966). É possivel que esta heterocromatina proximal seja de um tipo ainda não identificado pelas metodologias de bandamento a que estas espécies foram submetidas, abrindo espaço para que novas técnicas que 
permitam a identificação diferenciada da heterocromatina sejam aplicadas nestas espécies.

C. baccatum - O cariótipo desta espécie é constituído de 11 pares de cromossomos metacêntricos e um par submetacêntrico, sendo dois pares satelitados: um metacêntrico (par 3) e outro submetacêntrico (par 12) (Bertão \& Aguiar-Perecin, 1991; Bertão, 1993).

Para esta espécie foram analisadas as variedades 435, 530 e 2042 que apresentam cariótipos muito similares, com a maioria dos cromossomos metacêntricos com centrômero mediano. Destas apenas a variedade 530 apresenta três pares de cromossomos satelitados, sendo que no terceiro par o satélite não é muito conspicuo. Quanto ao padrão de bandas- $C$ foi observado um polimorfismo intraespecifico.

A var. 435 mostrou a presença de bandas-C grandes $\mathrm{e}$ pequenas distribuidas nas regiōes teloméricas. Foram observadas bandas no braço curto dos cromossomos 1, 2, 3 e 12 e em ambos os braços do cromossomo 4, 6, 7 e 8. As bandas-C maiores são encontradas no braço curto do cromossomo 3, correspondente ao satélite, e no braço longo do cromossomo 7. O satélite do cromossomo 12 mostrou-se levemente corado, bem como as bandas centroméricas presentes em quase todos os cromossomos (Figuras 1c e 2c).

A var. 2042 apresentou uma quantidade de heterocromatina maior que a observada na var. 435, embora com padrão de distribuição de bandas- $C$ semelhante, com presença de bandas teloméricas em pelo menos um dos braços cromossômicos, geralmente o braço longo, ou em ambos os braços. Foram observadas bandas teloméricas no braço curto dos cromossomos 4, 6, 7, 8 e 12, no braço longo dos cromossomos 5, 10 e 11, e em ambos os braços dos cromossomos 2 e 3 (Figuras $1 \mathrm{~d}$ e $2 \mathrm{~d}$ ).

As maiores bandas- $C$ foram encontradas no braço longo do 
cromossomo 5 e no satélite do par número 3. Bandas centroméricas também foram encontradas na maioria dos cromossomos, embora não apresentem coloração muito intensa, assim como o satélite do par 12 .

A var. 530 também apresenta padrão de bandamento-C semelhante ao das outras variedades de C. baccatum, com bandas-C distribuídas nas regiōes teloméricas do braço curto dos cromossomos 1, 3, 4 e 12, e em ambos os braços dos cromossomos 3, 8, 9 e 10. As bandas- $\mathrm{C}$ mais proeminentes nesta variedade são as do braço longo do cromossomo 3. Assim como nas outras variedade, bandas centroméricas ocorrem em quase todos os cromossomos, embora se corem fracamente, assim como o satélite do par 12 (Figuras 1e e 2e).

De uma forma geral o padrão de distribuição de bandas-C encontrado em C. baccatum apresenta relativa concordância ao padrão encontrado por Moscone et al. (1993, 1996) para bandamento-C e bandamento fluorescente. As discordāncias ocorrem com relação aos pares de cromossomos que apresentam bandas-C e com relação aos pares satelitados, mas concordam quanto a quantidade e distribuição de heterocromatina entre os cromossomos.

\subsubsection{Espécie selvagem}

A única espécie selvagem avaliada foi $C$. praetermissum $(2 n=24)$, cujo cariótipo é constituído por 11 pares de cromossomos metacêntricos e um submetacêntrico, sendo observados dois pares satelitados (pares 7 e 12) (Bertão \& Aguiar-Perecin, 1991, 1993ab; Bertão, 1993). A análise de metáfases coradas pelo bandamento-C revelou a presença de grandes blocos heterocromáticos distribuidos nas regiões teloméricas. Dos 12 pares de cromossomos, 11 pares 
apresentam bandas-C em pelo menos um dos braços, mostrando variação no tamanho, posição e intensidade. Bandas-C foram encontradas no braço curto dos cromossomos 7 e 12, correspondentes ao satélite, no braço longo dos cromossomos 3, 4, 5, 6, 10 e 11, e em ambos os braços do cromossomos 1, 2 e 8. Bandas centroméricas fracamente marcadas foram observadas na maioria dos cromossomos (Figuras 1f e 2f). Estes resultados são apresentados pela primeira vez e assemelham-se aos dados de bandamento-C e bandamento fluorescente descritos para C. pubescens por Moscone et al. (1993, 1996), onde foram descritos grandes blocos de heterocromatina assimetricamente distribuídos nas regiões teloméricas.

A avaliação do padrão de distribuição de heterocromatina constitutiva nas diferentes espécies, evidenciou um nitido aumento de heterocromatina em ordem crescente a partir de $C$. annuum, $C$. chinense, C. baccatum e C. praeternnissum. Um padrāo genérico é mantido para todas as espécies, com os cromossomos apresentando bandas- $C$ teloméricas, centroméricas e intercalares raras ou ausentes.

A presença de bandas centroméricas e satélites heretocromáticos na maioria dos cromossomos de Capsicum, sugerem uma estabilidade dessas caracteristicas, sendo consideradas como componentes antigos do genoma, enquanto as bandas terminais $\mathrm{e}$ intercalares são variáveis sendo consideradas como um componente mais novo dentro do genoma dessas espécies. Segundo Moscone et al. (1993), a presença de bandas teloméricas e intercalares representam um aumento adicional de heterocromatina no genoma dessa plantas, podendo ser interpretado como um avanço evolucionário.

Uma discussão mais elaborada com relação ao padrão de bandamento-C estabelecido por Moscone et al. (1993), para algumas espécies do gênero Capsicum, com o padrão de bandas estabelecido 
neste trabalho, é dificil uma vez que os cariótipos de bandamento-C estabelecidos pelo autor apresentaram equivocos quanto a identificação dos pares cromossômicos para algumas espécies, os quais foram corrigidos em uma nova publicação com a utilização de bandamento fluorescente (Moscone et al., 1996). Por exemplo, na espécie C. baccatum os pares cromossômicos $1,2,3,4,5,6,7,9$, e 10 identificados pelo bandamento- $C$, após a análise com fluorocromos base-específicos foram corrigidos para $5,1,2,9,6,10,3,7$ e 4 , respectivamente. Na espécie $C$. pubescens os cromossomos 4, 5, 5, 6, 7 e 9 foram corrigidos para 4, 5, $3,7,9$ e 6 , respectivamente.

\subsection{Coloração com nitrato de prata}

As regiōes organizadoras de nucléolos são regiōes dos cromossomos envolvidas na transcrição dos genes ribossômicos e, de acordo com sua atividade na intérfase anterior, podem ser visualizadas através da coloração com nitrato de prata (Miller et al., 1976). Após a coloração, as RONs são visualizadas sobre os cromossomos, constituindo-se em importantes marcadores citológicos.

Através da análise comparativa do funcionamento das RONs coradas pelo nitrato de prata, verificou-se a ocorrência de polimorfismo intra e interespecifico em espécies e variedades do gênero Capsicum.

Para coloração das regiōes organizadoras de nucléolo adotouse inicialmente a metodologia descrita por Howell e Black (1980), com algumas modificações. Embora tenha sido possivel observar fortes marcações das NORs com o uso de nitrato de prata, houve uma grande quantidade de "background". A redução deste foi possivel com a diminuição do tempo de fixação em etanol:ácido acético (3:1), associada à coloração imediata com nitrato de prata, após o esmagamento em 
ácido acético a 45\%, como sugerido por Hubbell (1985).

A coloração com nitrato de prata de cromossomos metafásicos de C. praetermissum, C. chinense e C. baccatum vars. 2042 e 435, revelou a presença de polimorfismo intraespecífico quanto ao número de RONs (Figuras 3, 4, 5 e 7). Foram observadas duas RONs por complemento haplóide para todas as espécies, exceto para $C$. chinense que apresentou apenas uma RON (Figura 3a). A análise dos núcleos interfásicos da variedade 530 de C. baccatum evidenciou a presença de 5 a 6 nucléolos, sugerindo a ocorrência de três RONs por lote haplóide (Figura 6). A confirmação destes dados poderá ser feita através da aplicação da técnica de hibridação in situ.

O procedimento de coloração com nitrato de prata mostrou concordãncia quanto ao cariótipo corado pelo método de Feulgen (Bertão, 1993) quanto à presença da região organizadora de nucléolo nas constricções secundárias dos pares satelitados. As RONs ocupam posições intersticiais como evidenciado no par metacêntrico 3 das var. 435 e 2042 e submetacêntrico 7 de C. praetermissum, ou terminais como no par subtelocêntrico 12 de $C$. chinense var. 2013, C. baccatum var. 2042 (Figura 5a) e var. 435 (Figura 6a), e de C. praetermissum (Figura 7). Na maioria dos casos, mesmo quando são terminais, as RONs podem ser reconhecidas como constrições secundárias nas preparações convencionais.

A avaliação de $C$. baccatum pela técnica de coloração com nitrato de prata por Moscone et al. (1995), evidenciou a presença de RONs em três pares de cromossomos, sendo dois metafásicos (1 e 3) e um satelitado (12) nos cultivares EAM 192 e EAM 209, e em quatro pares, sendo 3 metacêntricos (1, 3 e 10) e um satelitado (12) nos cultivares EAM 205 e EAM 206. 


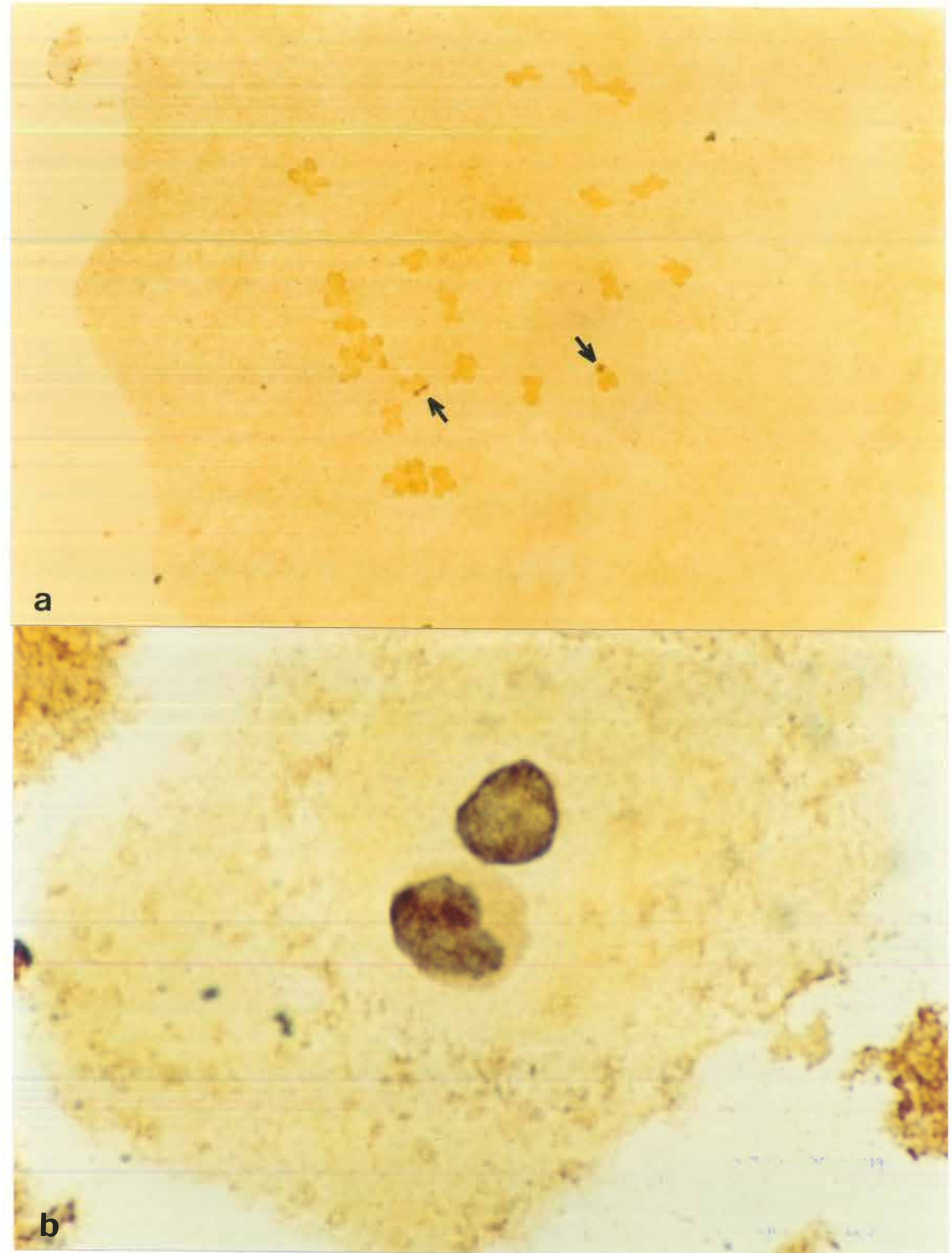

Figura 3 - C. chinenese var. 2013. Metáfase mitótica corada com nitrato de prata evidenciando duas RONs (a) e núcleo interfásico mostrando a presença de dois nucléolos (b). 


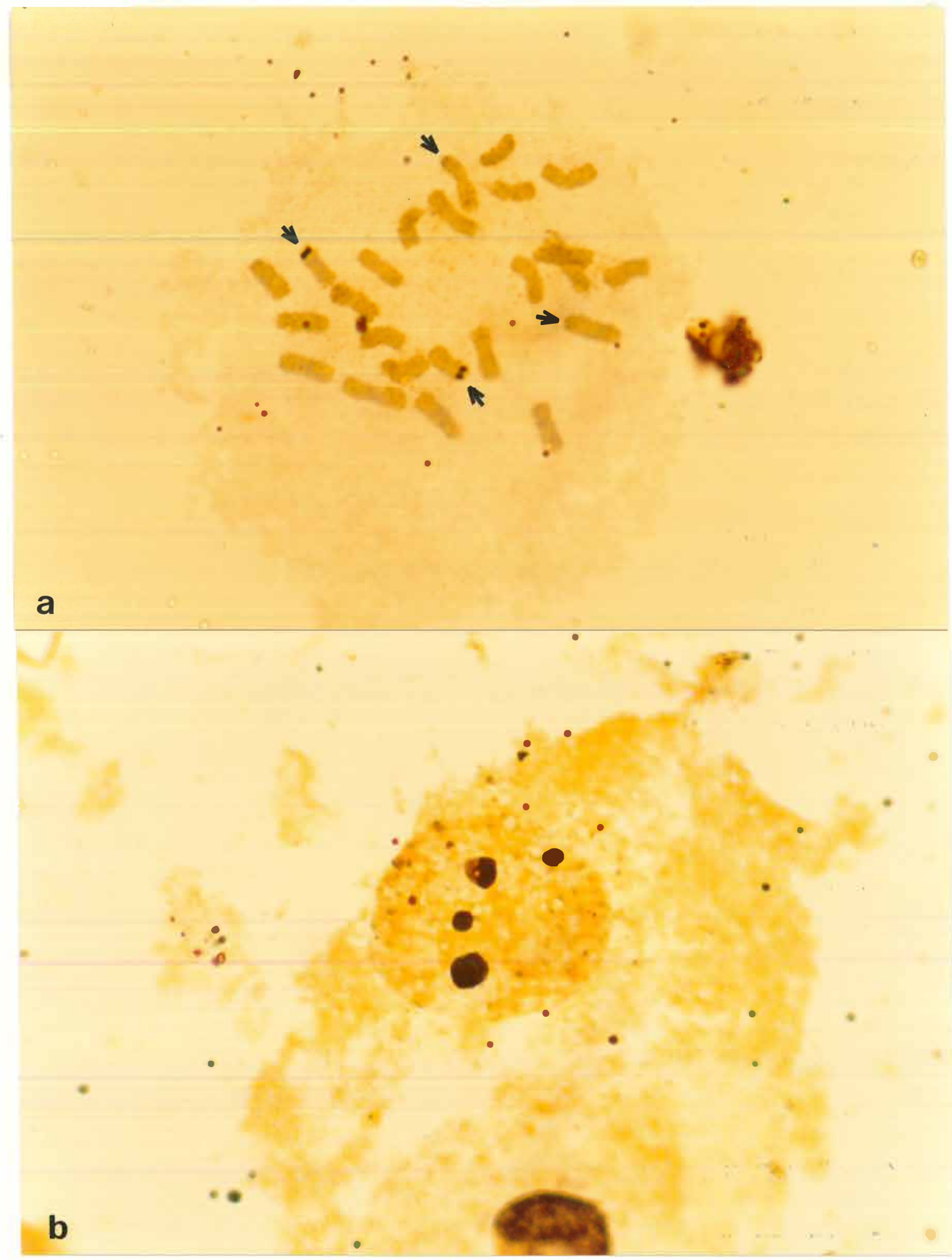

Figura 4 - C. baccatum var. 435. Metáfase mitótica corada com nitrato de prata evidenciando quatro RONs (a) e núcleo interfásico com quatro nucléolos (b). 


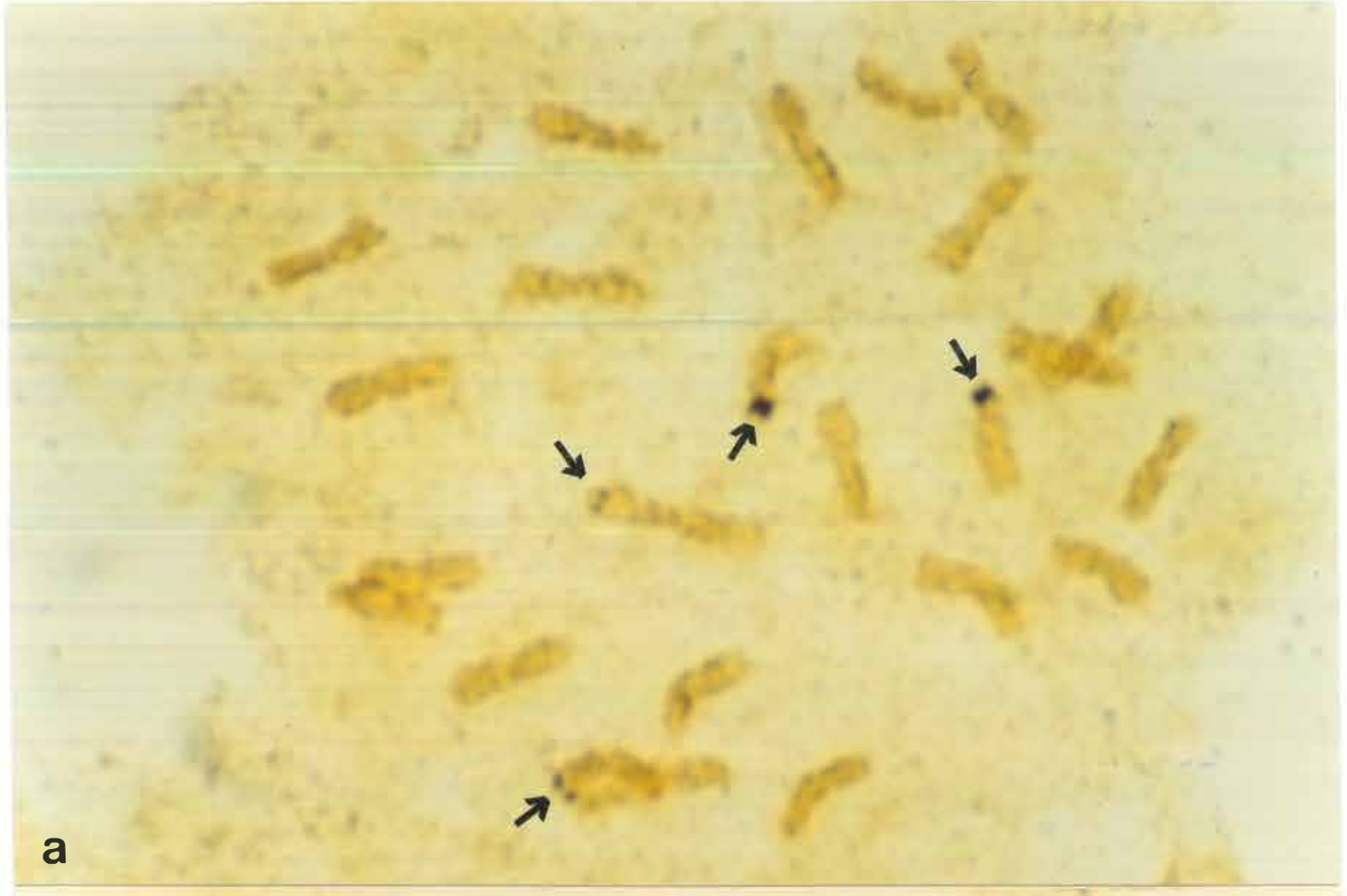

b

Figura 5 - C. baccatum var. 2042. Metáfase mitótica corada com nitrato de prata evidenciando a presença de quatro RONs (a) e núcleo interfásico mostrando quatro nucléolos (b). 


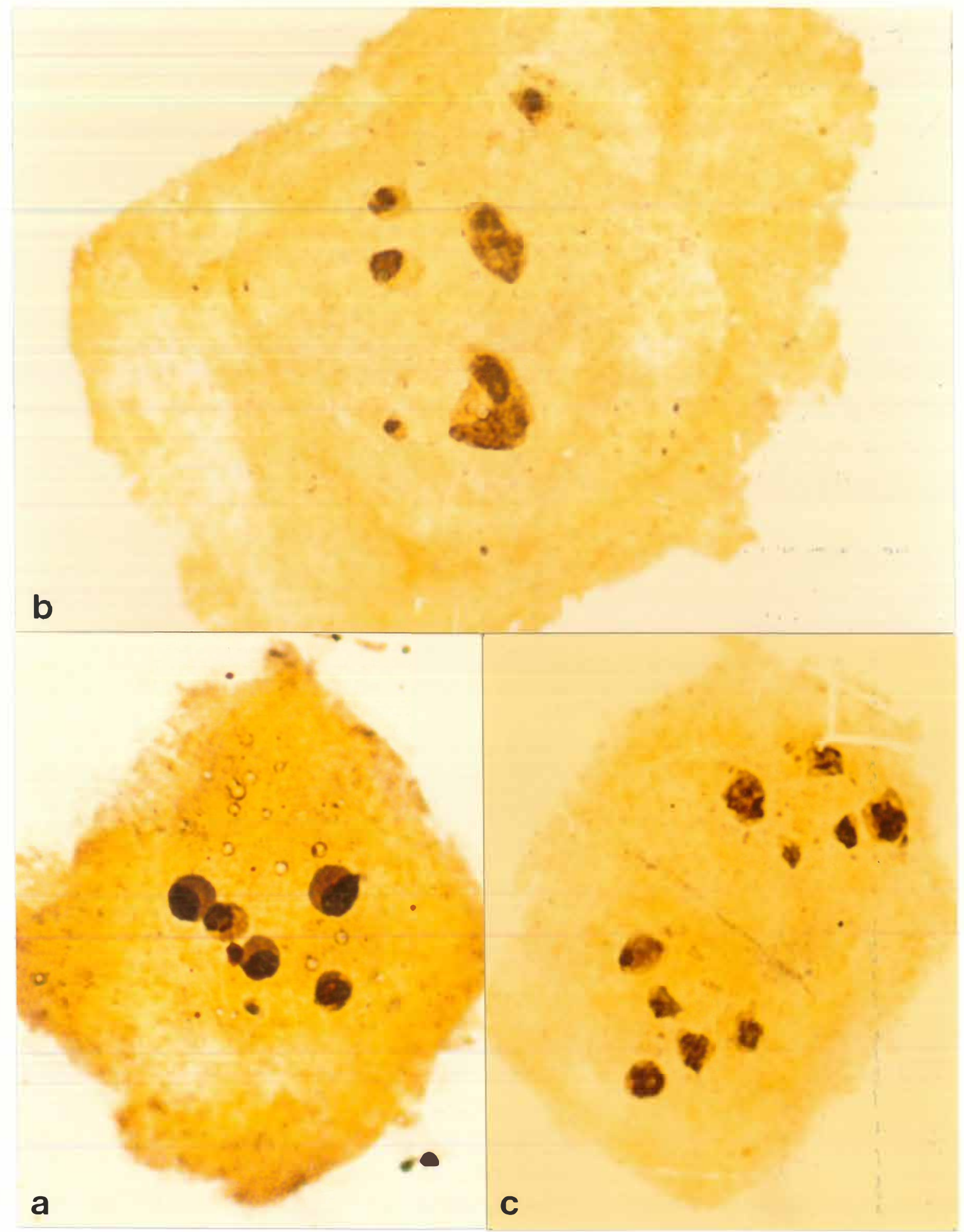

Figura 6 - C. baccatum var. 530. Núcleos interfásicos corados com nitrato de prata evidenciando cinco (a) e seis nucléolos (b), e telófase com cinco nucléolos (c). 


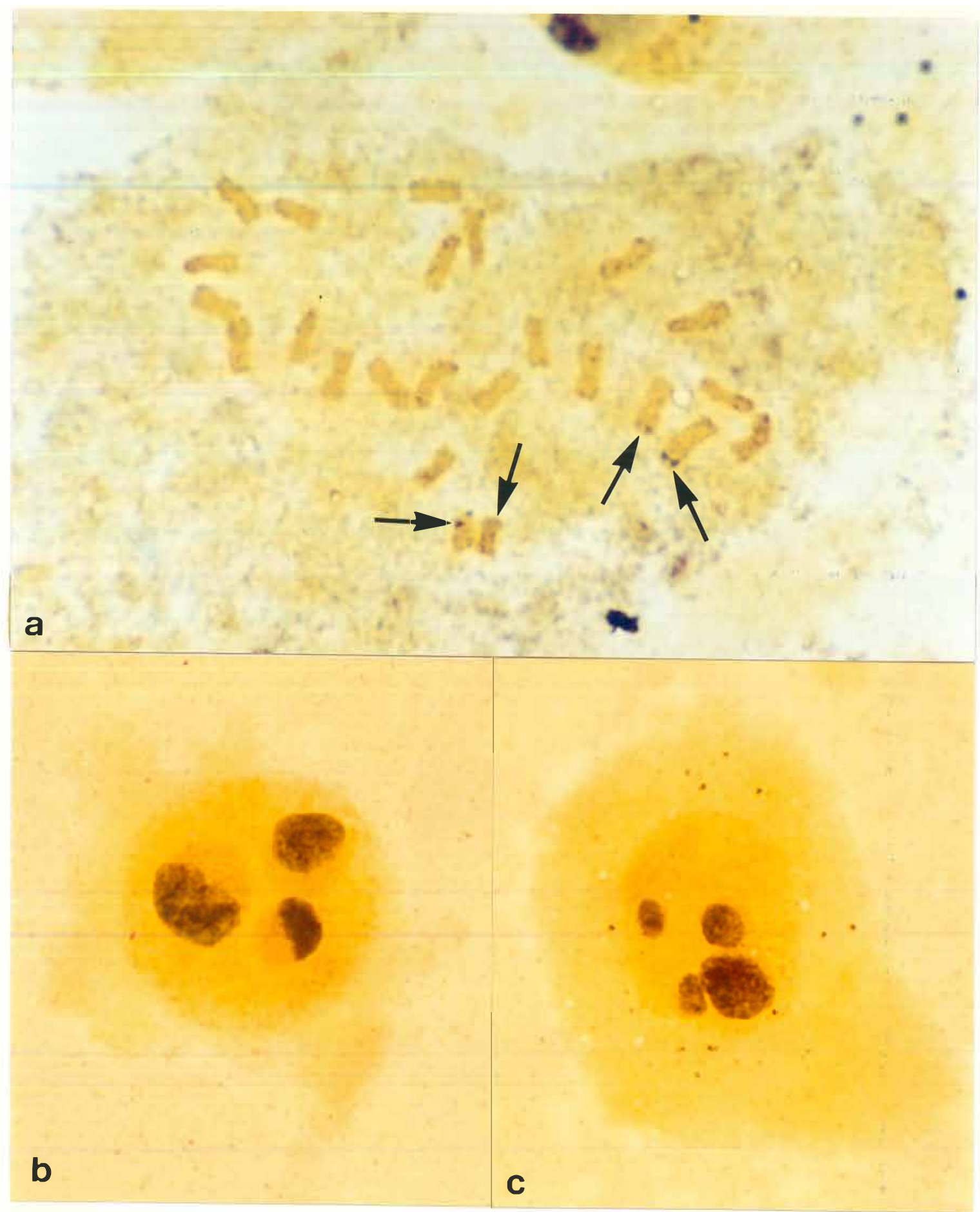

Figura 7 - C. praetermissum - BGH 6703. Metáfase mitótica corada com nitrato de prata evidenciando quatro RONs (a) e núcleos interfásicos com três (b) e quatro (c) nucléolos. 
$\mathrm{Na}$ literatura há poucos artigos referindo-se a um número elevado de RONs ativos em plantas diplóides, como encontrado por Moscone et al. (1995) para C. baccatum var. pendulum através de métodos de coloração com nitrato de prata. Elevado número de sítios rDNA foi detectado pelo método de hibridação in situ em Hordeum vulgare (Leitch e Heslop-Harrison, 1992) e algumas espécies de Brassica (Maluszyska e Heslop-Harrison, 1993).

Em todas as espécies investigadas, o número de RONs evidenciadas nos cromossomos metafásicos era maior, em relação ao número de nucléolos corados pela prata no núcleo interfásico. Em $C$. chinense, embora tenha sido evidenciada a presença de duas RONs correspondentes às constrições secundárias do par cromossômico satelitado, a maioria dos núcleos interfásicos apresentaram apenas um nucléolo. Núcleos interfásicos com dois nucléolos foram encontrados com menor frequência (Figura 3b). As espécies C. baccatum (vars. $435 \mathrm{e}$ 2042) e C. praetermissum também apresentaram um número menor de nucléolos no núcleo interfásico (geralmente três), em relação ao número de RONs (quatro) evidenciadas nos cromossomos corados pelo nitrato de prata (Figuras 5, 6 e 7).

Em Solanáceas a técnica de coloração com nitrato de prata para identificação da região organizadora de nucléolo foi aplicada em três gêneros: Solanum (Pijnacker e Ferweda, 1984, 1991), Cestrum (Berg e Greilhuber, 1992, 1993ab) e Capsicum (Moscone et al., 1995). Variação quanto ao número de RONs em relação ao número de nucléolos no núcleo interfásico é relatada para a maioria das espécies. Esta variação pode ser devido a fusão tardia de nucléolos (Lacadena et al., 1984).

Em Cestrum as RONs não são evidenciadas em cromossomos metafásicos pela coloração com nitrato de prata, sendo marcadas somente na intérfase, prófase e prometáfase (Berg e Greilhuber, 1992, 1993ab). 


\subsection{Bandamento Fluorescente}

O uso de fluorocromos base-especificos que têm afinidade por regiões cromossômicas ricas em $\mathrm{A}+\mathrm{T}$ (quinacrina e $\mathrm{DAPI}$ ) ou ricas em $\mathrm{G}+\mathrm{C}$ (cromomicina $\mathrm{A} 3$ e mitramicina), permite caracterizar a heterocromatina quanto a sua composição de bases. No presente trabalho foi realizado uma avaliação preliminar na espécie $C$. baccatum var. 2042 com o fluorocromo quinacrina seguindo a metodologia descrita por Vosa (1970). Nenhuma banda fluorescente foi observada, o que sugere que as sequências de heterocromatina nesta variedade não são ricas em A+T (Figura 8). Estes dados concordam com os resultados de Moscone et al. (1996), onde o uso de diferentes fluorocromos (cromomicina $\mathrm{A} 3$, DAPI) revelou a presença de sequências ricas em $\mathrm{G}+\mathrm{C}$ em cinco espécies cultivadas de Capsicum, incluindo C. baccatum, e somente $C$. pubescens apresentou uma pequena banda $\mathrm{A}+\mathrm{T}$ no braço longo do cromossomo 10.

A metodologia de bandamento-C estabelecida no presente trabalho, bem como a coloração com nitrato de prata, mostraram-se eficientes na determinação de bandas-C e identificação de RONs em cromossomos mitóticos do gênero Capsicum, sendo portanto, úteis para a avaliação de novas espécies, variedades e cultivares.

O uso de técnicas que permitem a identificação citoquímica da heterocromatina com o uso de fluorocromos base-específicos, bem como o uso da técnica de hibridação in situ para identificação de sítios rDNA, permitirá um melhor entendimento da evolução cariotípica ocorrida no gênero Capsicum. 


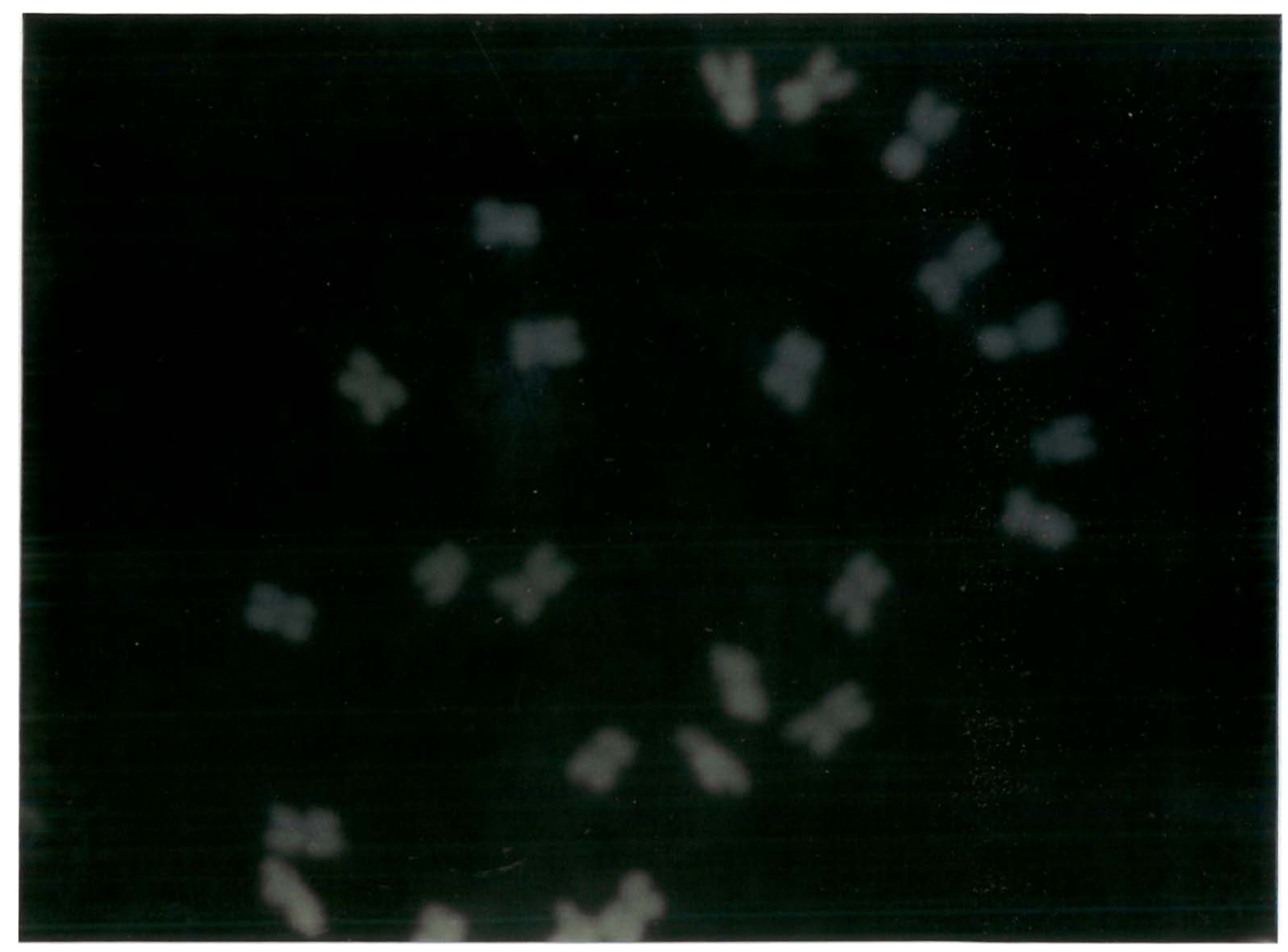

Figura 8 - Metáfase mitótica de C. baccatum var. 2042 corada com o fluorocromo quinacrina. Bandas fluorescentes não foram evidenciadas. 


\section{CONCLUSÕes}

1. O padrão de bandamento-C encontrado para as espécies de Capsicum analisadas é caracterizado pela presença de bandas-C grandes e pequenas distribuídas nas regiões teloméricas do braço longo ou curto, ou em ambos os braços do cromossomo; presença de bandas centroméricas na maioria dos cromossomos; e ausência de bandas intercalares.

2. Existe polimorfismo intra e interespecífico no gênero Capsicum quanto ao conteúdo e distribuição de heterocromatina, bem como quanto ao número de regiões organizadoras de nucléolo por lote haplóide, refletindo uma divergência evolucionária no gênero.

3. As variedades de C. baccatum apresentaram grande variação quanto ao número de sítios rDNA evidenciados pela coloração com nitrato de prata. A confirmação do número exato desses sítios poderá ser obtida através da aplicação da técnica de hibridação in situ.

4. A avaliação da var. 2042 de C. baccatum com o fluorocromo baseespecífico quinacrina não evidenciou a presença de bandas fluorescentes, o que sugere que as sequências heterocromáticas desta variedade pode ser rica em bases $G+C$. 
5. A metodologia de bandamento-C mostrou-se eficiente na caracterização e comparação de espécies e variedades do gênero Capsicum e esta, aliada a outras técnicas de bandamento cromossômico, bem como à técnicas de hibridação in situ, pode ser amplamente explorada na identificação cromossômica mais presisa neste gênero, adicionando um parâmetro para a caracterização e distinção das espécies. 


\section{REFERÊNCIAS BIBLIOGRÁFICAS}

AGUIAR-PERECIN, M.L.R. C-banding in maize. I. Band patterns. Caryologia, v.38, p.23-30, 1985.

ANDREWS, J. Peppers: the domesticated Capsicum. Austin: University of Texas Press, 1984. 170p.

BERG, C.; GREILHUBER, J. Cold-sensitive chromosome regions and their relation to heterochromatin in Cestrum parqui (Solanaceae). Genome, v.35, p.921-930, 1992.

BERG, C.; GREILHUBER, J. Cold sensitive regions and heterochromatin in Cestrum (Solanaceae): C. strigillatum, C. fasciculatum, and C. elegans. Plant Systematics and Evolution, v.85, p.133-151, 1993a.

BERG, C.; GREILHUBER, J. Cold-sensitive chromosome regions and heterochromatin in Cestrum aurantiacum (Solanaceae). Plant Systematics and Evolution, v.185, p.259-273, 1993b.

BERTÃO, M.R. Evolução cariotípca no gênero Capsicum (Solanaceae). Piracicaba, 1993. 148p. Dissertação (Mestrado) - Escola Superior de Agricultura "Luiz de Queiroz", Universidade de São Paulo.

BERTÃO, M.R. AGUIAR PERECIN, M.L.R. Caracterização cromossômica em espécies do gênero Capsicum. In: Revista Brasileira de 
Genética, v.14, p.77, 1991. Suplemento./ Apresentado ao 37. Congresso Nacional de Genética, Caxambu, 1991 - Resumo/

BERTÃO, M.R.; AGUIAR PERECIN, M.L.R. Variabilidade cariotipica em 20 variedades de quatro espécies selvagens. In: Revista Brasileira de Genética, v.16, p.192, 1993a. Suplemento./ Apresentado ao 39. Congresso Nacional de Genética, Caxambu, 1993 - Resumo/

BERTĀO, M.R. AGUIAR PERECIN, M.L.R. Evolução cariotípica no gênero Capsicum - análise de quatro espécies selvagens. In: Revista Brasileira de Genética, v.16, p.193, 1993b. Suplemento./ Apresentado ao 39. Congresso Nacional de Genética, Caxambu, 1993 - Resumo/

CARLUCCIO, F.; SACCARDO, F. Karyotupe studies in Capsicum. In: POCHARD, E. Capsicum 77. Comptes Rendues 3ème Congrès Eucarpia Piment, p.39-50, 1977. Avignon-Montfavet: Institut National de la Recherche Agronomique, 1977.

CASALI, V.W.D.; COUTO, F.A.A. Origem e botãnica de Capsicum. Informe Agropecuário, v.10, p.8-10, 1984.

DATTA, P.C. Karyology of indian varieties of Capsicum annuum Linn. (Solanaceae). Caryologia, v.21, p.121-126, 1968.

DIETRICH, A. J. J.; DE JONG.; J. H.; MULDER, R. J. P. Localization and variation of the constitutive hetrochromatin in Petunia hybrida. Genetica, v.55, p.85-91, 1981.

ESHBAUGH, W.H. A biosytematic and evolutionary study of Capsicum baccatum (Solanaceae). Brittonia, v.22, p.31-43, 1970. 
ESHBAUGH, W.H. Genetic and biochemical systematic studies of chili peppers (Capsicum-Solanaceae). Bulletin of the Torrey Botanical Club, v.102, p.396-403, 1976.

FILION, W.G.; VOSA, C.G. Quinacrine fluorescense studies in Paris polyphytla. Canadian Journal of Genetics and Cytology, v.22, p.417-420, 1980.

FRIEBE, B.; ENDO, T.R.; GILL, B.S. Chromosome-banding methods. In: FUKUI, K.; NAKAYAMA, S. Plant chromosomes: laboratory methods, 1996. cap. 7, p.123-153.

HANSON, R.E.; ISLAM-FARIDI, M.N.; PERCIVAL, E.A.; CRANE, C.F.; JI, Y; McKNIGHT, T.D.; STELLY, D.M.; PRICE, H.J. Distribuition of $5 \mathrm{~S}$ and 18S rDNA loci in a tetraploid cotton (Gossypium hirsutum L.) and its putative diploid ancestors. Chromosoma, v. 105, p.55-61, 1996.

HEISER, C.B; PICKERSGILL, B. Names for the cultivated Capsicum species (Solanaceae). Taxon, v. 18, p.277-283, 1969.

HOWELL, W.M.; BLACK, D.A. Controlled silver-sataining of nucleolus organizer regions with a protective colloidal developer: A 1-step method. Experientia, v.36, p.1014, 1980.

HUBBELL, H.R. Silver staining as na indicator of active ribosomal genes. Stain Technology, v.60, p.285-294, 1985.

JENSEN, R.J.; McLEOD, M.J.; ESHBAUGH, W.H.; GUTTMAN, S.I. Numerical taxonomic analyses of allozymic variation in Capsicum (Solanaceae). Taxon, v.28, p.315-327, 1979. 
KATSIOTIS, A; HAGIDIMITRIOU, M.; HESLOP-HARRISON, J.S. The close relationship between the $\mathrm{A}$ and $\mathrm{B}$ genomes in Avena L. (Poaceae) determined by molecular cytogenetic analysis of total genomic, tandemly and dispersed repetitive DNA sequences. Annals of Botany, v.79, p.103-109, 1997.

LACADENA, J.R.; CERMEÑO, M.C.; ORELLANA, J.; SANTOS J.L. Evidence for wheat-rye nucleolar competition (amphiplasty) in triticale by silver-staining procedure. Theoretical and Applied Genetics, v.67, p.207-213, 1984.

LEITCH, I. J.; HESLOP-HARRISON, J. S. Physical mapping of the 18S5.8S-26S rRNA genes in barley by in situ hibridization. Genome, v.35, p.1013-1018, 1992.

LIMAYE, V. A.; PATIL, V. Karyomorphological studies in the genus Capsicum Linn. Cytologia, v.54, p.455-463, 1989.

LINARES, C; GONZÁLEZ, J.; FERRER, E.; FORMINAYA, A. The use of double fluorescence in situ hybridization to physically map the positions of 5S rDNA genes in relation to the chromosomal location of $18 \mathrm{~S}-5.8 \mathrm{~S}-26 \mathrm{~S}$ rDNA and a $\mathrm{C}$ genome specific DNA sequence in the genus Avena. Genome, v.39, p.535-542, 1996.

MALUSZYSKA, J.; HESLOP-HARRISON, J.S. Physical mapping of rDNA loci in Brassica species. Genome, v.36, p.774-781, 1993.

McLEOD, M.J.; ESHBAUGH, W.H.; GUTTMAN, S.I. An electrophoretic study of Capsicum (Solanaceae): The purple flowered taxa. Bulletin of the Torrey Botanical Club, v.106, p.326-333, 1979. 
MILLER, O.J.; MILLER, D.A.; DEV, V.G.; TANTRAVAHI, R.; CROCE, C.M. Expression of a human and suppression of mouse nucleolar organizer activity in mouse-human somatic cell hybrids. Proceedings of the National Academy of Sciences of the U.S.A., v.73, p.4531-4535, 1976.

MOSCONE, E.A. Chromosome studies on Capsicum (Solanaceae) I. Karyotype analysis in C. chacoënse. Brittonia, v.42, p.147-154, 1990.

MOSCONE, E.A.; LAMBROU, M.; HUNZIKER, A.T.; EHRENDORFER, F. Giemsa C-banded karyotypes in Capsicum (Solanaceae). Plant Systematics and Evolution, v.186, p.213-229, 1993.

MOSCONE, E.A.; LOIDL, J.; EHRENDORFER, F.; HUNZIKER, A.T. Analysis of active nucleolus organizing regions in Capsicum (Solanaceae) by silver staining. American Journal of Botany, v. 82, p.276-282, 1995.

MOSCONE, E.A.; LAMBROU, M.; EHRENDORFER, F. Fluorescent chromosome banding in the cultivated species of Capsicum (Solanaceae). Plant Systematics and Evolution, v.202, p.37-63, 1996.

MOURAS, A. Caryogramme du Nicotiana tabacum et tentative d'identification des chromosomes par banding. Genetica, v.60, p.41-48, 1982.

MOURAS, A.; WILDENSTEIN, C.; SALESSES, G. Analysis of karyotype and C-banding pattern of Nicotiana plumbaginifolia using two techniques. Genetica, v.68, p.197-202, 1986. 
OTHA, Y. Cytogenetical studies in the genus Capsicum. I. C. frutescens x C. annuum. Japan Journal of Genetic, v.36, p.647-651, 1961.

PARDUE, M.L.; GALL, J.C. Chromosome localization of mouse satelite DNA. Science, v.168, p.1356-1358, 1970.

PICKERSGILL, B. Relationships between weedy and cultived forms in some species of chili peppers (genus Capsicum). Evolution, v.25, p.683-691, 1971.

PICKERSGILL, B. Taxonomy and the origin and evolution of cultivated plants in the New World. Nature, v.268, p.591-595, 1977.

PICKERSGILL, B. Cytogenetics and evolution of Capsicum L. In: TSUCHIYA, T.; GUPTA, P.K. Chromosome engineering in plants: genetics, breeding, evolution. Amsterdam, Elsevier, 1991. pt. B, p.39-60.

PIJNAKER, L.P.; FERWERDA, M.A. Giemsa C-banding of potato chromosomes. Canadian Journal of Genetics and Cytology, v.26, p.415-419, 1984.

PIJNAKER, L.P; FERWERDA, M.A. Nucleolar organizer function in developing potato calli. Theoretical and Applied Genetics, v.82, p.587-592, 1991.

PRINGLE, G. J.; MURRY, B.G. Karyotypes and C-banding patterns in species of Cyphomandra Mart. ex Sendtner (Solanaceae). Bot. J. Linn. Soc. v.111, p.331-342, 1993.

RAMANNA, M.S. ; WAGENVOORT, M. Identification of trissomic series in diploid Solanum tuberosum L., group tuberosum. Chromosome identification. Euphytica, v.25 p.233-240, 1976. 
SATO, S.; HIZUME. M.; KAWAMURA, S. Relathionship between secondary constrictions and nucleolus organizing regions in Allium cepa. Caryologia, v.34, p.431-440, 1980.

SCHWARZACHER, T.; AMBROS, P.; SCHWEIZER, D. Application of Giemsa banding to orchid karyotype analysis. Plant Systematics and Evolution, v.134, p.293-297, 1980.

SHOPOVA, M. Studies in the Genus Capsicum. I. Species Differentiation. Chromosoma, v.19, p.340-348, 1966.

SINCLAIR, J.H.; BROWN, D.D. Retention of common nucleotide sequences in the ribossomal deoxyribonucleic acid of eukaryotes and some of their physical characteristics. Biochemistry, v.10, p.2761-2769, 1981.

SINHA, N.P. The somatic chormosomes and meiosis in Capsicum. Indian Journal of Gentics and Plant Breeding, v.10, p.36-42, 1950.

SMITH, P.G; HEISER, C.B. Taxonomic and genetic studies on the cultivated peppers, C. annuum L. and C. frutescens L. Ameriacan Journal of Botany, v.38, p.362-368, 1951.

TANKSLEY, S.; BERNATZKY, R.; LAPITAN, N.L.; PRINCE, J.P. Conservation of gene repertoire but not gene order in peper and tomato. Proceedings of the National Academy of Sciences USA, v.85, p.6419-6423, 1988.

TYAGI, B. R.; GILL, B.S. C-banded karyotype of Hyoscyamus muticus L. Journal of Heredity, v.81, p.401-402, 1990. 
VERMA, R.S.; BABU, A. Human chromosomes: principles and techniques. New York: McGraw-Hill, 1995. 419p.

VOSA, C.G. Heterochromatin recognition with fluorochromes. Chromosoma, v.30, p.366-372, 1970.

VOSA, C.G. Plant chromosome banding and cytotaxonomy. In: AGUIARPERECIN, M.L.R.; SODERO, P; BANDEL, G. Tópicos de citogenética e evolução de plantas, 1. p.17-25. Anais. Ribeirão Preto, SP, Sociedade Brasileira de Genética, 1985.

VOSA, C.G. Chromosome banding: plants. Genome, v.31, p.474-475, 1989.

VOSA, C.G.; MARCHI, P. On the quinacrine fluorescence and Giemsa staining patters of the chromosomes of Vicia faba. Gionarle Botanico Italiano, v.106, p.151-159, 1972a.

VOSA, C.G.; MARCHI, P. Quinacrine fluorescence and Giemsa staining in plants. Nature New Biology, v.237, p.191-192, 1972b.

WIJSMAN, H.J.W.; De JONG, J.H.; PEDERSEN; T.M. On the interelationships of certain species of Petunia III. The position of $P$. linearis and P. calycina. Acta Botanica Neerland, v.32, p.323-332, 1983.

XU, J.; EARLE, E.D. High resolution physical mapping of 45S (5.8S, $18 \mathrm{~S}$ and 25S) rDNA gene loci in tomato genome using a combination of karyotyping and FISH of pachytene chromosomes. Chromosoma, v.104, p.545-550, 1996. 